\title{
Influence of water saturation on the strength characteristics and deformation behavior of hardened cement paste backfill
}

Jie Wang ( $\sim 18810582761 @ 163 . c o m)$

ustb

Jianxin Fu

USTB: University of Science and Technology Beijing

\section{Research Article}

Keywords: water saturation, cemented paste backfill, secant modulus, strength difference, box plot, fractal dimension

Posted Date: March 29th, 2021

DOI: https://doi.org/10.21203/rs.3.rs-351748/v1

License: (c) (i) This work is licensed under a Creative Commons Attribution 4.0 International License.

Read Full License 


\section{Influence of water saturation on the strength characteristics and 2 deformation behavior of hardened cement paste backfill}

3 Jie Wang ${ }^{1,2, *}$, Jianxin $\mathrm{Fu}^{1,2, *}$, Weidong Song ${ }^{1,2, *}$ and Yongfang Zhang ${ }^{1,2}$

${ }^{1}$ School of Civil and Resources Engineering, University of Science and Technology Beijing, Beijing 100083, China

${ }^{2}$ State Key Laboratory of High-Efficient Mining and Safety of Metal Mines of Ministry of Education, University of Science and Technology Beijing, Beijing 100083, China

* Correspondence: $18810582761 @ 163 . c o m$ (J.W.); fujun0011 @ 126.com (J.F.); songwd@ustb.edu.cn (W.S.)

10 Abstract

In this study, a uniaxial compression experimental was conducted to examine the mechanical properties of hardened cemented paste backfill (CPB) with different water saturations $(0.18 \%, 4.98 \%, 9.30 \%, 21.6 \%, 32.8 \%$, and $100 \%)$. The experimental results demonstrated that water saturation loosened the overall structure of the $\mathrm{CPB}$, which led to the deterioration of its mechanical properties. As the water saturation increased, the uniaxial compressive strength (UCS), residual strength, strength difference, deformation modulus, secant modulus, $E_{50}$ (the secant modulus at $50 \%$ of the UCS), peak strain, and elastic strain decreased, while the plastic strain ratio increased. The UCS, $E_{50}$, and peak strain demonstrated exponential function relationships with the water saturation. After the peak point, when the water saturation was less than $20 \%$, the strength of the CPB decreased rapidly, and when the water saturation was greater than $30 \%$, the strength decreased slowly. Lastly, the plastic strain, the strain at $50 \%$ of the UCS, and the strain at the maximum secant modulus conformed to the normal distribution, and the water saturation had a minimal impact on these three strains. The fractal dimension, $\mathrm{D}$, of the cracks in the CPB increased exponentially with increasing water saturation and demonstrated a negative linear correlation with the UCS.

Keywords

water saturation; cemented paste backfill; secant modulus; strength difference; box plot; fractal dimension

\section{Introduction}

The stope-and-fill method of mining underground metal ore is commonly used worldwide, especially in China, Canada, and Australia, because of its significant advantages in controlling surface subsidence, reducing the discharge of waste rock and tailings, and making efficient use of mineral resources [1-5]. Filling the mined-out area with tailings can greatly reduce the exposed area of the roof, increase mining safety, improve resource recovery, and increase the mine's profitability [6-10].

It is important to study the mechanical properties of CPB, which not only affect its stability but also establish the stability of the surrounding rock and roof, thus determining the 
safety of the mining operation [11-14]. Numerous studies, in laboratory and field-scale tests, have illustrated that the mechanical strength and stability performance of CPB is greatly affected by both internal and external parameters, especially in the presence of water [15-20]. Cao et al. [21-22] analyzed the influence of structural factors (number of structural planes, angle of structural planes, and filling interval time) on the mechanical characteristics of CPB. Full et al. [23] quantitatively analyzed the influence of sulfate on the strength development of CPB and predicted the CPB's strength evolution.

Water is one of the most basic components of the CPB, and thus, plays a vital role [2628]. First, it affects the efficiency of transporting the backfill slurry in the pipeline, and, second, the backfill hydration reaction requires a large amount of water [29-30]. Shortage of water can cause the cement hydration to end prematurely. However, excessive water in the CPB negatively influences its strength and durability [31-33]. As the mining continues to extend horizontally and vertically, the stope will inevitably expand to the bottom of rivers, lakes, and even the ocean [24-25]. When this occurs, excessive water penetrates the CPB along the cracks in the rock mass. When the CPB contacts excessive water, its stability changes, which can adversely impact safety. Because accurately controlling the water saturation of backfill is difficult, the existing relevant research has primarily focused on dry and fully saturated backfill [34-35]. Liu et al. [36] conducted uniaxial compression strength (UCS) tests on CPB in dried, original, and fully saturated states, and found that the strength trend was: dried state $>$ original state > saturated state. When the CPB specimen was saturated state, the UCS was notably reduced. Hou et al. [37] analyzed the dynamic behavior of dry and water-saturated backfill and, with the help of damage mechanics theory, performed an in-depth study of the evolution of the backfill damage for both conditions.

Most backfill materials are exposed to humidity, and the seepage water in the cracks of the rock mass and the moisture in the air inevitably affect the mechanical properties of the backfill material. At this time, the CPB in different stopes or in different positions of the same stope is affected by different water saturation (0 to 100\%). However, only studying the influence of complete drying and saturation conditions on the mechanical properties of CPB will inevitably have limitations. At present, there are relatively few studies on the effect of water saturation on the mechanical properties of backfill. The environmental conditions of the $\mathrm{CPB}$ vary with mines and stopes of the same mine. If we study the mechanical behavior of CPB under completely dry (water saturation of $0 \%$ ) or wet (water saturation of $100 \%$ ) conditions, the conclusions obtained will not be representative of most mine conditions, and this creates difficulty with providing guidance to the mines. Therefore, it is essential to study the mechanical behavior of CPB and analyze the mechanism of its strength deterioration under different water saturation conditions to provide a reference for mines to control their $\mathrm{CPB}$ stability.

From the above analysis, it is of great theoretical and practical significance to study the influence of water saturation on the strength characteristics and deformation behavior of CPB. The specific objectives of this research are: firstly, to qualitatively analyze the influence of water saturation on stress-strain curve, strength characteristics and deformation behavior of hardened CPB; secondly, to quantitatively analyze the influence of water saturation and peak strength, peak strain, elastic strain and secant modulus of hardened CPB; and thirdly, to discuss the strength degradation mechanism and internal crack distribution of water-saturated $\mathrm{CPB}$ specimens. 


\section{Materials and Methods}

84

The materials and methods section should contain sufficient detail so that all procedures can be repeated. It may be divided into headed subsections if several methods are described.

\subsection{Material characteristics}

The tailings used in this experiment are from Shandong Province, China. The particle size distribution of tailings is measured by SA-CP3 particle size analyzer (Figure1). First, the tailings particles were dispersed into the coal liquid. Due to gravity, the tailings particles settled, and the settling speeds of the different particle sizes were different. The differences in the tailings particle settlement was obtained using the optical system. The optical signal was then transformed into an electrical signal. This electrical signal was converted into data after being amplified by the amplifier, and finally, the test result was output. The median particle size of the tailings was $107.33 \mu \mathrm{m}$, and the average particle size was $144.26 \mu \mathrm{m}$. The weighing method determined that the density of the tailings was $2.53 \mathrm{~kg} / \mathrm{m}^{3}$. An x-ray diffractometer was used to analyze the chemical composition of the tailings, and the results in Table 1 . The binder was ordinary Portland cement, type 42.5R. The test molds were transparent acrylic tubes with an inner diameter of $50 \mathrm{~mm}$ and a height of $100 \mathrm{~mm}$. The sidewall of the molds was marked with a scale, and several filter holes were distributed across the bottom.

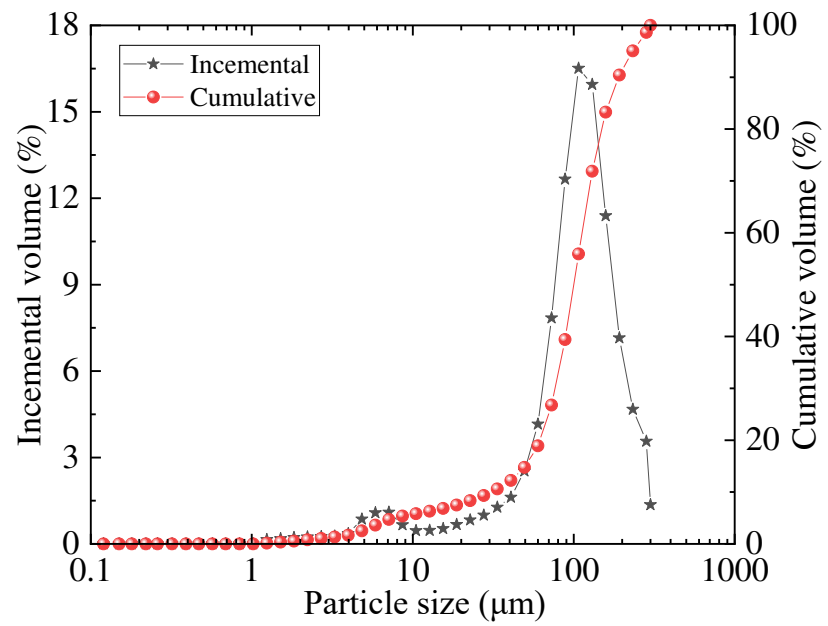

Figure 1: Incremental and cumulative PSD curves of the tailings.

Table 1: Chemical composition of the tailings.

\begin{tabular}{ccccccccc}
\hline Composition & $\mathrm{SiO}_{2}$ & $\mathrm{Al}_{2} \mathrm{O}_{3}$ & $\mathrm{CaO}$ & $\mathrm{MgO}$ & $\mathrm{P}$ & $\mathrm{Fe}$ & $\mathrm{S}$ & $\mathrm{Au}$ \\
\hline Content $(\%)$ & 65.7 & 14.3 & 1.88 & 0.49 & 0.08 & 3.05 & 0.13 & $<0.01$ \\
\hline
\end{tabular}

\subsection{Experimental procedures}

\subsubsection{Specimen fabrication}

The "dry first, then wet mix" method was adopted for the CPB preparation process, to make the slurry mixing more uniform. The tailings and Portland cement, type 42.5R were first dry-mixed for $3 \mathrm{~min}$; the proper amount of water was added, and then the mixture was stirred for $3 \mathrm{~min}$. The cement-to-tailings ratios of all specimens were 1:4, and the slurry concentrations were $75 \%$. The uniformly mixed slurry was poured into the molds, which were then placed in a curing box having a constant temperature of $20 \pm 1{ }^{\circ} \mathrm{C}$ and humidity of $95 \% \pm 5 \%$. After 7 $\mathrm{d}$ of curing, the $\mathrm{CPB}$ specimens were separated from the external molds and placed in the 
112 curing box again. After a total of $60 \mathrm{~d}$ of curing, the 24 prepared specimens were removed from

113 the curing box to undergo further treatment.

\section{$114 \quad 2.2 .2$ Specimen saturation}

115 CPB specimens with different amounts of water saturation were prepared as follows and as shown in Figure 2:

(1) All the prepared specimens were placed in the constant temperature and humidity curing box for natural drying for at least 2 weeks.

(2) The specimens were then dried for more than $6 \mathrm{~d}$ in a $105^{\circ} \mathrm{C}$ oven, and their masses were measured every 1-2 day. When the mass of a specimen no longer changed, it was removed from the oven and its mass recorded as md.

(3) All specimens were placed in the laboratory and dried naturally for 1 day.

(4) All specimens were water-saturated under a vacuum condition, and their masses were measured every 1-2 day. When the mass of a specimen no longer changed, it was removed, and its mass was recorded as mw. Before UCS testing, the mass of each specimen was measured and recorded as mi. The water saturation of the specimen is calculated as follows:

$$
w_{s}=\frac{m_{i}-m_{d}}{m_{w}-m_{d}}
$$

where $w_{s}$ is the water saturation of the specimen, $m_{i}$ is the mass of the specimen before compression, $m_{w}$ is the mass of the specimen at full saturation, and $m_{d}$ is the mass of the completely dry specimen.

(5) Five water-saturated specimens were selected for UCS testing in water (Figure3), the results of which were recorded as the group WS.

(6) Three water-saturated specimens were placed in the laboratory for 1 day, after which the UCS testing was conducted, and the results were recorded as the group AD1.

(7) Five water-saturated specimens were placed in the laboratory for 2 weeks. The UCS tests were then performed, and the results were recorded as the group AD.

(8) Three water-saturated specimens were placed in the laboratory for 2 weeks. The specimens were placed in water for 30 seconds, the UCS testing was conducted, and the results were recorded as the group IW.

(9) Three water-saturated specimens were dried in a $105^{\circ} \mathrm{C}$ oven for 6 days, and the UCS testing was performed, the results of which were recorded as the group OD.

(10) The last five water-saturated test pieces were placed in a vacuum tube for 1 day and then underwent UCS testing. The results were recorded as the group VD.

\begin{tabular}{|c|c|c|c|c|}
\hline \multirow{2}{*}{ Group } & \multirow{2}{*}{ Number } & \multicolumn{3}{|c|}{ Water saturation process } \\
\hline & & Step 1 & Step & \\
\hline WS & 5 & 2 weeks in curing box & UCS test ir & \\
\hline AD1 & 3 & & $1 d$ in Lab & UCS test \\
\hline AD & 5 & n of 10 & 2 weeks in Lab & UCS test \\
\hline IW & 3 & $1 \mathrm{~d}$ in Laboratory & 2 weeks in Lab $\rightarrow 30 \mathrm{~s}$ i & $r \rightarrow$ UCS test \\
\hline OD & 3 & Water saturation & $6 d$ in oven of $105^{\circ}$ & UCS test \\
\hline VD & 5 & under vacuum state & $1 d$ in vacuum tub & UCS test \\
\hline
\end{tabular}

Figure 2: CPB specimen water saturation processes. 
146

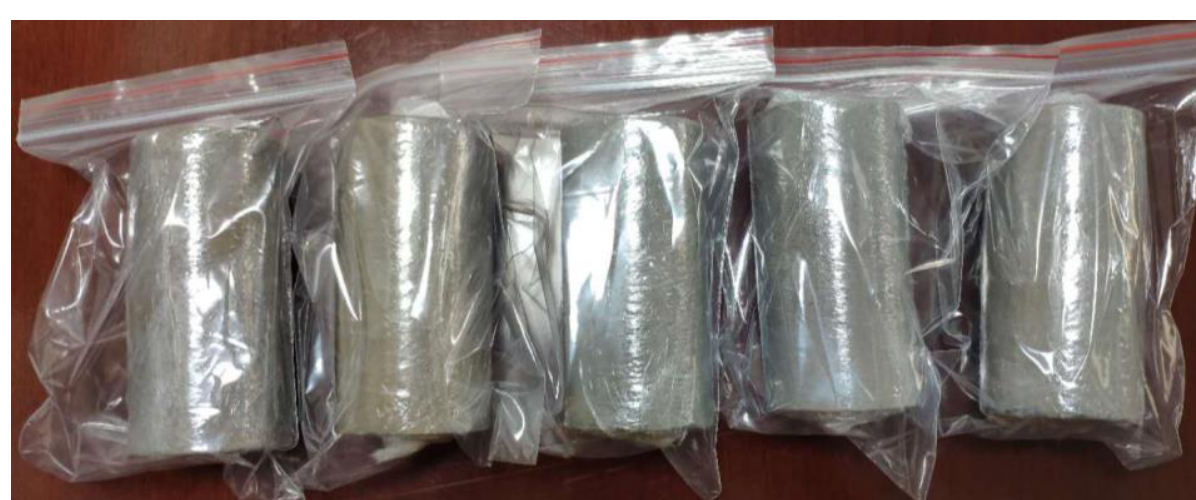

Figure 3: CPB specimens are sealed in plastic bags.

After the water saturation treatment, all the specimens were packaged in plastic wrap to prevent environmental influence on their water saturation. Testing was conducted on the VD group to verify the plastic wrap's effectiveness in isolating the specimens. After a specimen was enclosed in plastic wrap and placed in the laboratory for 2 hours, a quality control test showed that the mass of the specimen increased negligibly, by $0.006 \mathrm{~g}$. Therefore, the plastic wrap provided an effective isolation environment.

\subsubsection{Unconfined compressive strength tests}

The UCS test was performed on the prepared CPB specimens, which had an outer diameter of $50 \mathrm{~mm}$ and a height of $100 \mathrm{~mm}$. The equipment used was a GAW-2000 electrohydraulic servo testing machine (Figure 4). The loading rate of uniaxial compression test is $0.5 \mathrm{~mm} / \mathrm{min}$, and the stress and strain data of CPB can be exported by Excel format.

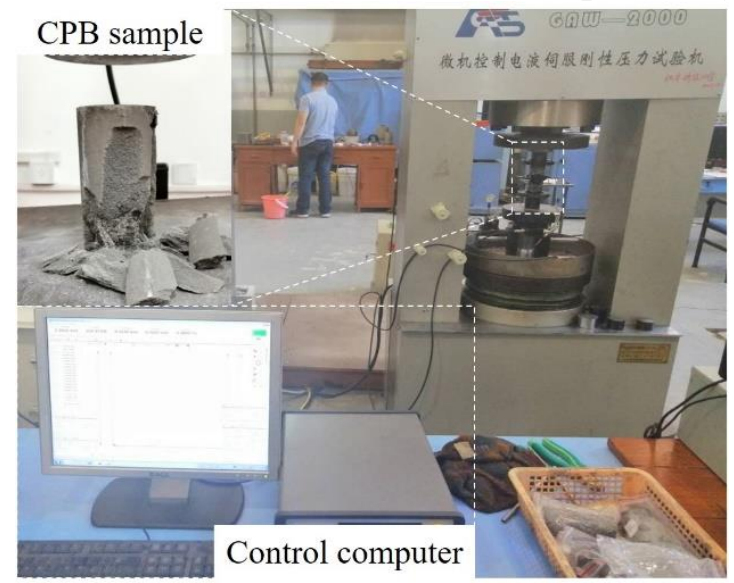

Figure 4: GAW-2000 electro-hydraulic servo testing machine.

\section{Results and analysis}

The primary test results of this study are shown in Table 2 . The values listed are the average of each group of test results. In the table, UCS is the uniaxial compressive strength; ores is the residual strength; deformation modulus is the ratio of the peak stress to the strain at the peak stress.

Table 2: Primary test results.

\begin{tabular}{ccccc}
\hline Group & $w_{\mathrm{s}}(\%)$ & $\begin{array}{c}\text { Deformation } \\
\text { modulus }(\mathrm{MPa})\end{array}$ & UCS $(\mathrm{MPa})$ & $\sigma_{\text {res }}(\mathrm{MPa})$ \\
\hline OD & 0.18 & 699.3 & 5.65 & 1.48 \\
VD & 4.98 & 628.9 & 4.90 & 1.35 \\
AD & 9.30 & 571.4 & 3.92 & 0.947 \\
IW & 21.6 & 416.7 & 2.70 & 0.695
\end{tabular}




$\begin{array}{ccccc}\text { AD1 } & 32.8 & 370.4 & 2.07 & 0.407 \\ \text { WS } & 100 & 247.6 & 1.40 & 0.212\end{array}$

\subsection{Influence of water saturation on the stress-strain curve}

The stress-strain curves for all specimens are displayed in Figure 5, and they show that, with increasing water saturation, the strength of the cemented tailings backfill gradually decreased a total of $75.2 \%$, from the peak value of $5.65 \mathrm{MPa}$ (average value) to $1.40 \mathrm{MPa}$ (average value). With increasing water saturation, the slope of the curve before the peak point decreased, that is, the modulus decreased. Additionally, with increasing water saturation, the curve after the peak point changed notably. When the water saturation was less than $20 \%$, the strength decreased rapidly after the peak point. When the water saturation was greater than $30 \%$, the strength decreased slowly after the peak point. The residual strength showed a pattern similar to that of the peak strength; with increasing water saturation, the residual strength decreased gradually. Further, the stress-strain curve of the low-saturation backfill surrounds the stress-strain curve of the high-saturation backfill.

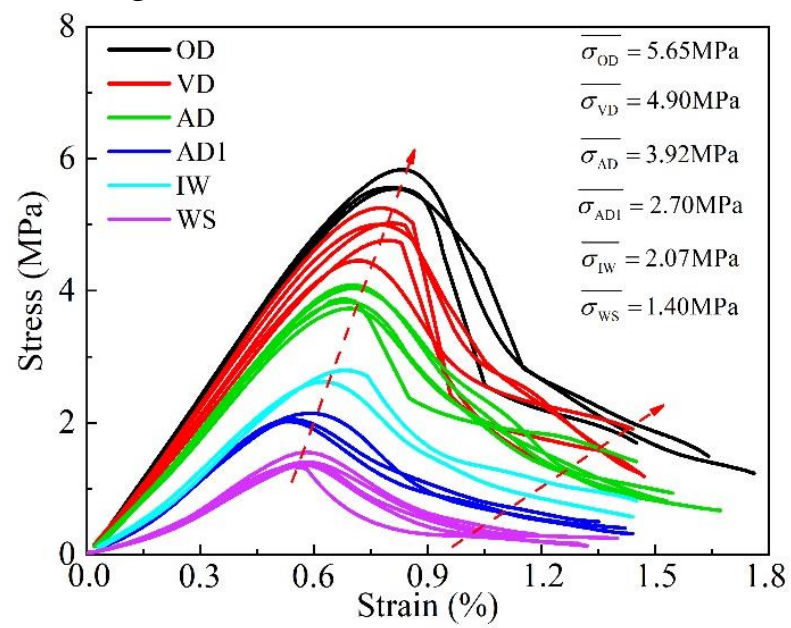

Figure 5: Stress-strain curve of the specimens with different water saturation values.

Figure 5 and Table 2 also show that the deformation modulus of the CPB decreased with increasing water saturation. When the water saturation was $0.18 \%$, the deformation modulus of the CPB was $699.3 \mathrm{MPa}$. When the water saturation increased to $4.98 \%$, the deformation modulus of the CPB decreased by $10.1 \%$, to $628.9 \mathrm{MPa}$. Increasing the water saturation to $9.30 \%$ decreased the deformation modulus by $9.1 \%$, to $571.4 \mathrm{MPa}$. When the water saturation was $21.6 \%$, the deformation modulus was $416.7 \mathrm{MPa}$, a decrease of $12 \%$. For water saturation values of $32.8 \%$ and $100 \%$, the deformation modulus decreased by $12 \%$ and $13 \%$, to 370.4 $\mathrm{MPa}$ and 247.6 MPa, respectively. Overall, when the water saturation increased from $0.18 \%$ to $100 \%$, the deformation modulus of the CPB decreased by $451.7 \mathrm{MPa}$, a reduction of $56 \%$.

\subsection{Influence of water saturation on strength}

Referring to the related research results in the field of rock mechanics [38-39], this study used exponential, logarithmic, and power functions to fit and analyze the relationship between the CPB strength and water saturation. The results are shown in Figure 6.

Figure 6 shows that, with increasing water saturation, the UCS of the CPB decreased rapidly. The UCS was particularly sensitive to water saturation in the lower saturation range, with a slight change in water saturation causing a rapid decrease in the strength. As the water saturation increased, the sensitivity of the UCS to the water saturation decreased significantly. The residual strength demonstrated similar properties. When the water saturation increased from $0.11 \%$ to $32.8 \%$, the uniaxial compressive strength and residual strength decreased by 
$63.4 \%$ and $72.5 \%$, respectively; when the water saturation increased from $32.8 \%$ to $100 \%$, the strength decreased by $32.4 \%$ and $47.9 \%$, respectively.

The parameters and R2 values of the fitting functions are also provided in Figure 6, and they show that the degree of fit of the exponential function was higher than for the logarithmic and power functions. The exponential function well represents the observed characteristic of a slower strength change in the later stages, and the water saturation can be taken as zero, while the water saturation of the logarithmic and power functions cannot.
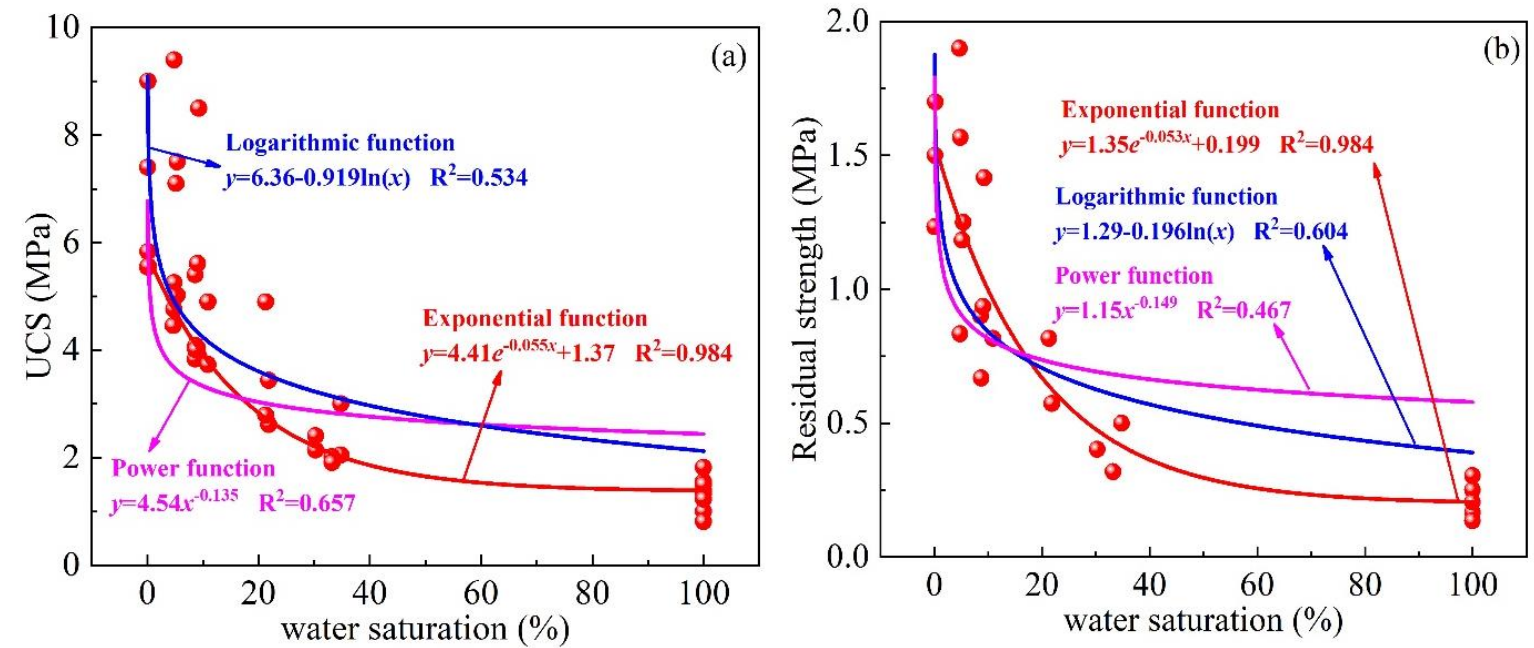

Figure 6: Relationship between the strength and water saturation of the CPB specimens. (a) UCS. (b) residual strength.

\subsection{Influence of the water saturation on the strain}

It is well known that the total stress-strain curve of CPB can be divided into compaction, elastic, and plastic deformation parts prior to the peak point. $[8,40]$. The strain at the peak point can be calculated with Eq. 3 if the strain produced in the compaction part is ignored, then

$$
\varepsilon_{f}=\varepsilon_{e}+\varepsilon_{p}
$$

where $\varepsilon_{f}$ is the strain at the peak point, $\varepsilon_{e}$ is the elastic strain, and $\varepsilon_{p}$ is the plastic strain.

The relationship between these three strain values and water saturation, and the relationship between the plastic strain ratio and water saturation is shown in Figure 7 . The plastic strain ratio is defined as follows:

$$
\varepsilon_{p}^{*}=\varepsilon_{p} / \varepsilon_{f}
$$

Three fitting function types-exponential, logarithmic, and power functions-were used to fit the relationship between the strain and water saturation; the results shown in Figure 7a-c. It can be seen from Figure 7a-b that with increasing water saturation, the peak strain and elastic strain demonstrate patterns of change similar to that of the strength. The greater the water saturation was, the lower the peak strain and elastic strain were, and, as the water saturation increased, the sensitivity of the peak strain and elastic strain to the water saturation decreased. It can be seen from Figure 7a-b that there is no clear relationship between the plastic strain and the water saturation, which is a discrete distribution, distributed between 0.00115 and 0.0019 , among which the points between 0.0014 and 0.0016 are the greatest. Figure $7 \mathrm{~d}$ shows that although the plastic strain distribution was relatively discrete, the plastic strain ratio gradually increased as the water saturation increased. In the lower water saturation interval, the plastic strain ratio increased rapidly, and when the water saturation exceeded $30 \%$, the plastic strain ratio decreased rapidly.

As can also be seen from Figure 7, the exponential function had the best degree of fit for the relationships between the water saturation and the peak point and elastic strains. However, the power function had the greatest degree of fit to the relationship between the water saturation 


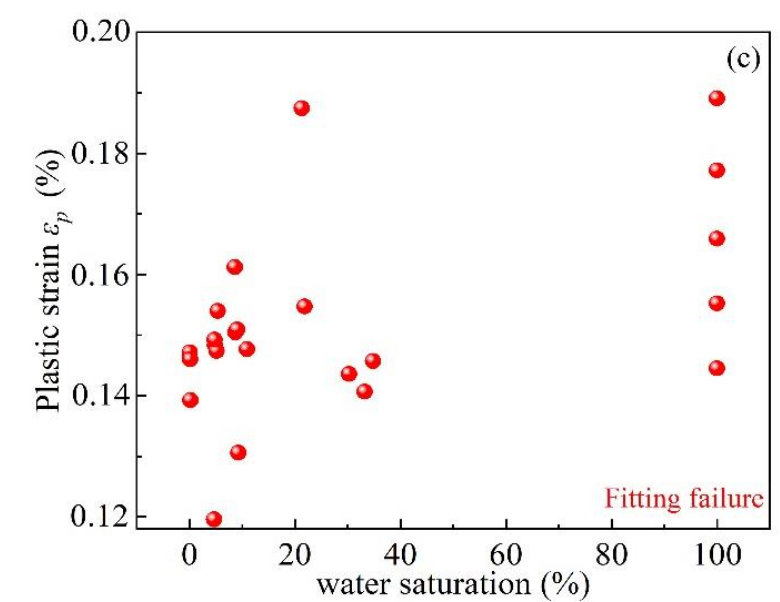

(a)
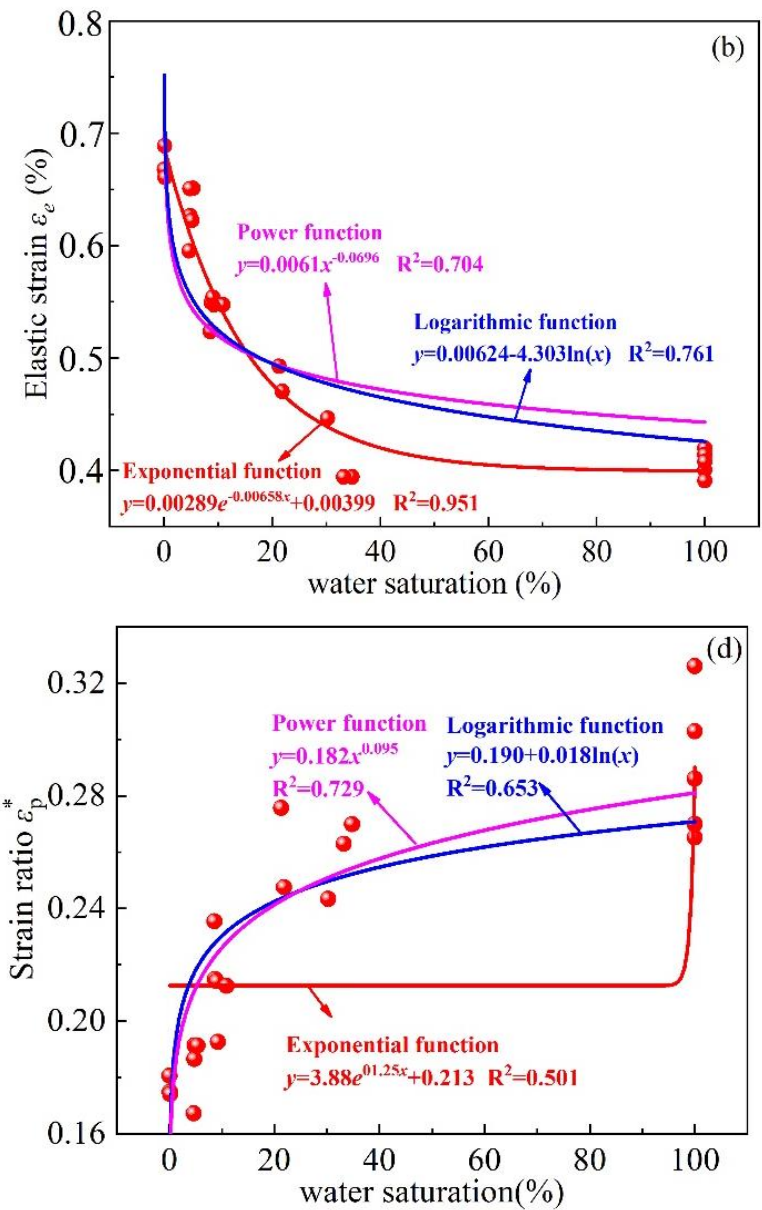

Figure 7: Relationship between the strains and water saturation. (a) $\varepsilon_{f .}$ (b) $\varepsilon_{e}$. (c) $\varepsilon_{p}$. (d) $\varepsilon_{p}{ }^{*}$.

\subsection{Influence of the water saturation on the secant modulus}

Secant modulus is an important backfill parameter and reflects the deformation characteristics of the backfill. One specimen from each group was chosen for studying the secant modulus. The results are shown in Figure 8
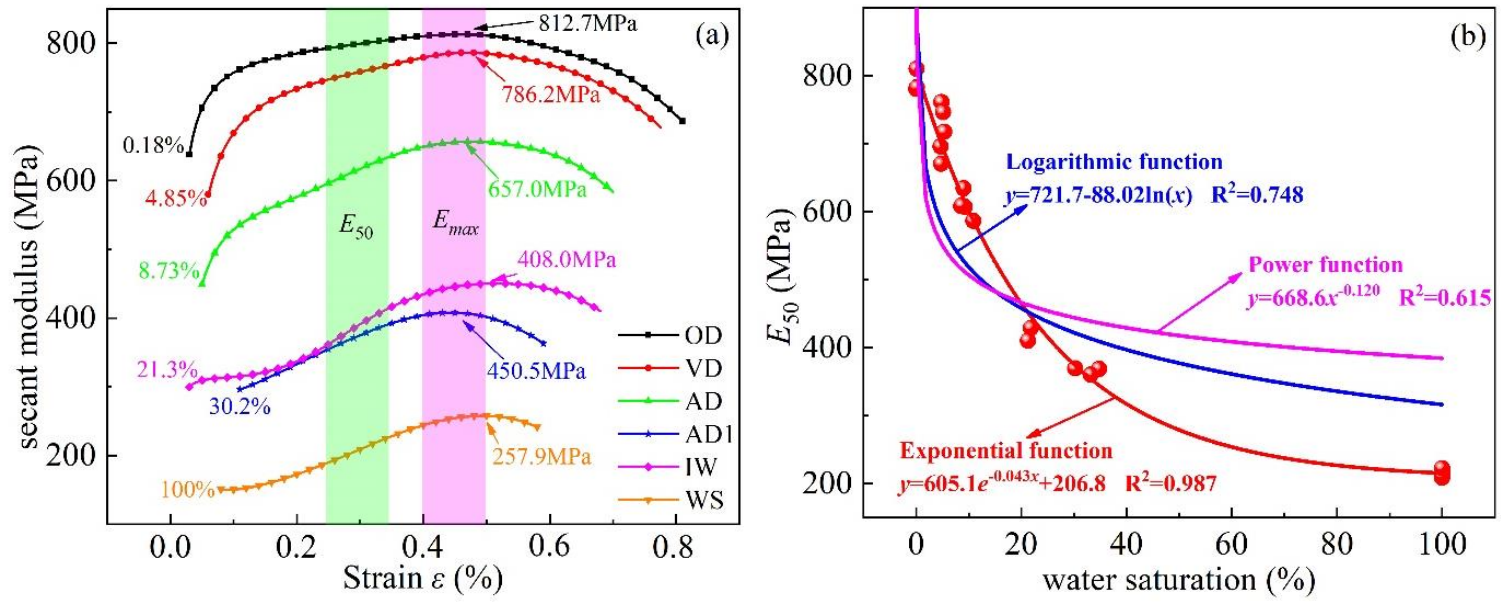

Figure 8: The evolution of the CPB modulus. (a) secant modulus. (b) $E_{50}$.

It can be seen from Figure 8a that the secant modulus decreased with increasing water saturation, and the maximum secant modulus decreased from 812.7 MPa to 257.9 MPa when 
the water saturation increased from $0.18 \%$ to $100 \%$, representing a decrease of $68.3 \%$. For specimens with any water saturation, the secant modulus demonstrated a trend of first increasing and then decreasing; the critical point was $0.5 \%$. For the specimens with water saturations of $0.18 \%, 4.85 \%$, and $8.73 \%$, the secant modulus increased rapidly at low strain, indicating that the specimens had a compression region. The secant modulus then increased slowly and remained almost unchanged, indicating that the specimen entered the stage of linear change. For the specimens with water saturations of $21.3 \%, 30.2 \%$, and $100 \%$, the secant modulus was always in the stage of uniform growth, indicating that there was no apparent compression stage in the $\mathrm{CPB}$, which clearly demonstrated plastic characteristics.

The two columnar zones in Figure $8 \mathrm{a}$ are the strain ranges of $E_{50}$ (the secant modulus at $50 \%$ of the UCS) and the maximum secant modulus of each specimen. It can be seen from Figure 8a that the strain distribution was between 0.0025 and 0.0035 when the specimen reached $E_{50}$ and between 0.004 and 0.005 when it reached the maximum secant modulus.

The $E_{50}$ of each specimen was calculated as provided in Figure 8b, which shows that, with increasing water saturation, the $E_{50}$ demonstrated a similar relationship with the strength and strain, that is, when the water saturation was low, the $E_{50}$ was particularly sensitive to the water saturation, and the rate of change decreased as the water saturation increased. When the water saturation increased from $0.11 \%$ to $32.8 \%$, the $E_{50}$ decreased by $53.7 \%$; when water saturation increased from $32.8 \%$ to $100 \%$, the E50 decreased by $41.1 \%$.

Exponential, logarithmic, and power functions were also used to fit the relationship between the $E_{50}$ and water saturation. The fitting parameters and $\mathrm{R}^{2}$ are shown in Figure $8 \mathrm{~b}$. The exponential function had the highest degree of fit and characterizes the rule of change of the $E_{50}$ with water saturation better than that by logarithmic or power functions.

In conclusion, the water saturation had a significant effect on the mechanical properties of the CPB. With increasing water saturation, the UCS, $\varepsilon_{f}, \varepsilon_{e}$, and $E_{50}$ all demonstrated an exponential function relationship, as provided in Eqs. 5-8. These results support the research of references [41-45].

$$
\begin{gathered}
U C S=4.41 e^{-0.055 w_{s}}+1.37 \\
E_{50}=605.1 e^{-0.043 w_{s}}+206.8 \\
\varepsilon_{f}=0.00269 e^{-0.0689 w_{s}}+0.00563 \\
\varepsilon_{e}=0.00289 e^{-0.0658 w_{s}}+0.00399
\end{gathered}
$$

\section{Discussion}

\subsection{Relationship between the strength difference and water saturation}

Based on the study results, the relationship between the uniaxial compressive strength and the water saturation of the CPB can be expressed by the exponential function shown in Eq. 9:

$$
\sigma_{f}\left(w_{s}\right)=a e^{-b w_{s}}+c,\left(0 \leq w_{s} \leq 100\right)
$$

where $\sigma_{f}\left(w_{s}\right)$ is the UCS of the specimen having a water saturation of $w_{s}$, and $a, b$, and $c$ are constants. The parameter $b$ is a dimensionless constant defining the rate of strength loss with increasing water content and characterizing the material's sensitivity, with larger values corresponding to more sensitive materials.

Parameters a and c can be obtained by testing the strength of the water-saturated and dry specimens. However, more experiments would be needed to determine $b$, so, for practical engineering, it is useful to simplify the method for determining this parameter. 
Based on Eq. 9, the difference between the strength of any water saturation specimen and that of fully saturated specimens can be directly obtained as follows:

$$
\Delta \sigma_{f}=a e^{-b w_{s}}
$$

Using Eq. 9, the values of a and c can be determined, and Eq. 10 can be transformed into:

$$
\Delta \sigma_{f}=\left[\sigma_{f}(0)-\sigma_{f}(100)\right] e^{-b w_{s}}
$$

In the actual experimental process, there is a certain discreteness between different CPB specimens. If it is assumed that the difference between the actual strength and the experimental value, as calculated by Eq. 11 , is $1 \%$ of the actual strength of the fully saturated CPB, and the specimen reaches full saturation, then:

$$
e^{-100 b}=\frac{1 \% \times \overline{\sigma_{w s}}}{\sigma_{f}(0)-\sigma_{f}(100)}
$$

Eq. 12 can be further modified to obtain:

$$
b=-\ln \left(\frac{1 \% \times \overline{\sigma_{w s}}}{\sigma_{f}(0)-\sigma_{f}(100)}\right) / 100
$$

Based on the results of the experiment and fitting analysis, when the CPB was fully saturated, the average strength of the CPB specimen was $1.405 \mathrm{MPa}, \sigma_{f}(0)-\sigma_{f}(100)=4.41$. From this, $b=0.0575$ can be obtained, and the formula for the strength difference is as follows:

$$
\Delta \sigma_{f}=4.41 e^{-0.0575 w_{s}}
$$

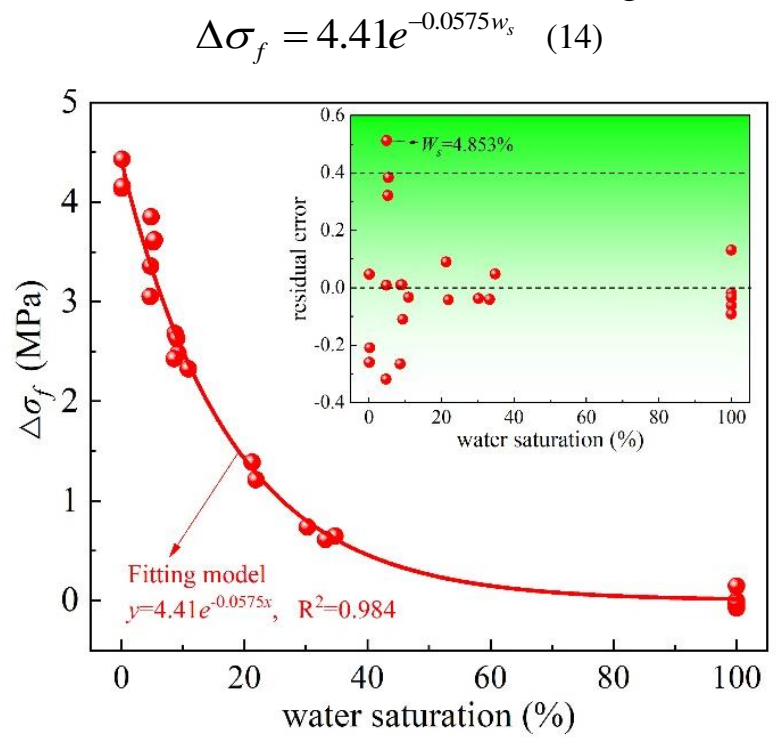

Figure 9: Relationship between the strength difference and water saturation.

Eq. 14 is used for fitting and precision analysis. Figure 9 shows the fitting results between the strength difference and water saturation, and the upper right corner of Figure 9 shows the residual value after fitting. It can be observed that $\mathrm{R}^{2}$ is 0.984 after fitting with Eq. 14, and the residual distribution is $(-0.4,+0.4)$. Only one abnormal point was noted, when the water saturation is $4.853 \%$, illustrating the extremely high degree of fit of Eq. 14. Therefore, in mining engineering, Eq. 14 can be used to predict the strength of CPBs having different water saturations.

\subsection{Interdependency of strain and water saturation}

It can be seen from the results in Sections 3.3 and 3.4 that, with increasing water saturation, the plastic strain, the strain corresponding to the $E_{50}$, and the maximum secant modulus are discrete distributions. The laws of distribution of these three variables were studied as follows. 
First, the degrees of dispersion and laws of distribution of the three strains were analyzed by using a box plot [46-47]. A typical box plot is shown in Figure 10. The distribution range of a group of data can be intuitively determined using the box plot, and the form of distribution of the data set can also be preliminarily determined. Data points that exceed the upper and lower boundaries of the box plot are considered abnormal values.

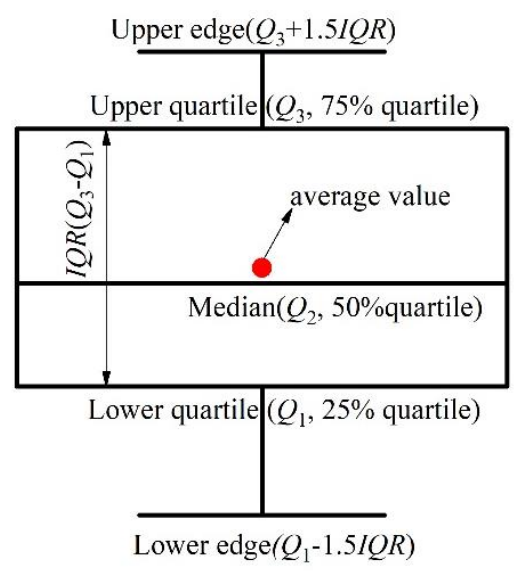

Figure 10: Box plot.

The box plots of the plastic strain, the strain at the $E_{50}$, and the strain at the maximum secant modulus are shown in Figure 11. Figure 11a shows the box plot of the plastic strain, which shows that most of the plastic strains of the specimens with different water saturations were distributed within the upper and lower edges. There were a total of 16 data points, of which 11 were distributed within the range of the box body from 0.00155 to 0.00145 , so it can be preliminarily determined that the plastic strain followed a normal distribution. Figure $11 \mathrm{~b}$ is the box plot of the strain corresponding to $50 \%$ of the UCS and the strain corresponding to the maximum secant modulus. It can be seen from Figure 10b that the data points for both strains were within the upper and lower edges, there were no abnormal points, and the average values and median lines of both strains were almost equal, indicating that the two groups of data have better concentrations. The strain at $50 \%$ of the UCS was mostly distributed in the range of $0.00315-0.00348$. There were 13 points in total, with five data points between the upper quartile and the upper edge and five between the lower quartile and the lower edge. The strain at the maximum secant modulus was primarily distributed in the range of 0.0045-0.005. There were 14 data points in total, with four data points between the upper quartile and the upper edge and five between the lower quartile and the lower edge. Therefore, it can be preliminarily determined that the two strains conformed to the normal distribution.
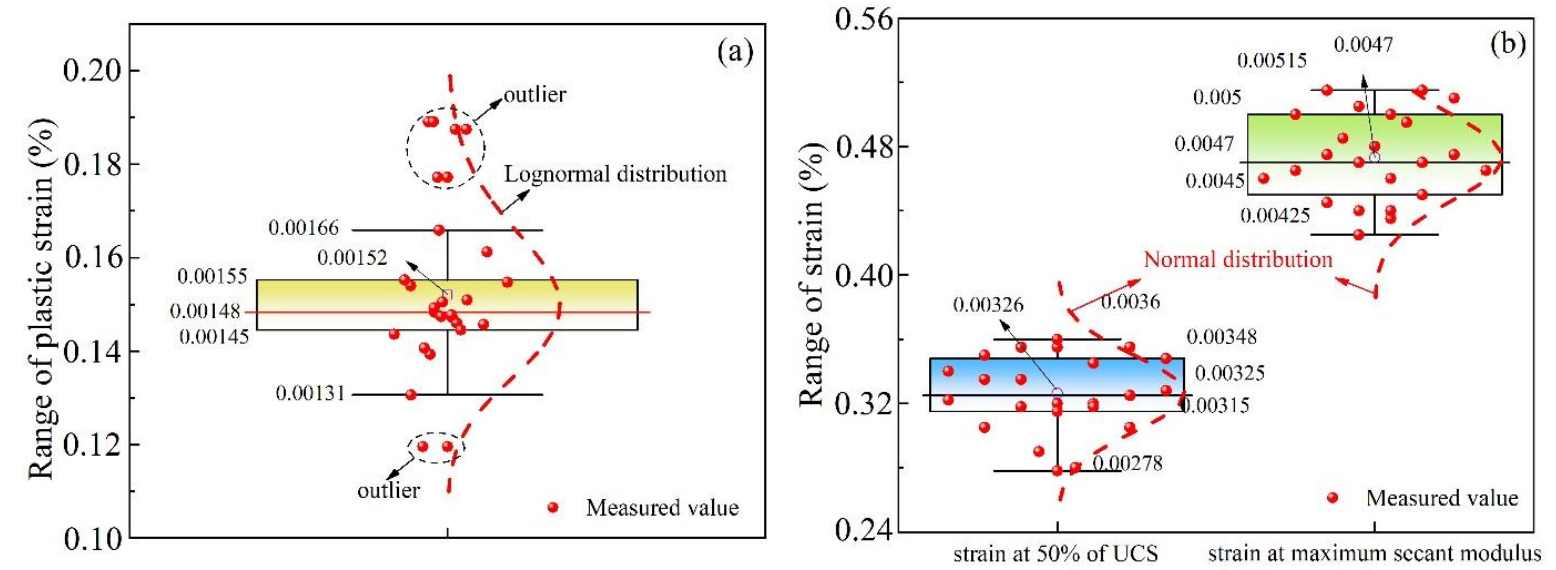

Figure 11: Box plots of (a) plastic strain and (b) strain at E50 and maximum secant modulus.

To further determine the distribution of the three strains, a distribution histogram and a Q-Q plot of each strain were developed, as shown in Figure 12-14. Figure 12 is the distribution 
histogram of the plastic strain, which shows that most of the plastic strains were concentrated between 0.00140 and 0.00155 , accounting for $60.9 \%$ of the total. There were few other interval distributions, but, due to its non-symmetric distribution, the plastic strain was closer to a lognormal distribution. It can also be seen from Figure 12b that most of the data points were distributed along the reference line. Using the K-S test, the P-value was 0.384 , which is greater than the 0.05 reference value, indicating that it conformed to the typical lognormal distribution characteristics. Similarly, the strain at $50 \%$ of the UCS and the strain at the maximum secant modulus underwent distribution fitting and the K-S test, which indicated that both conformed to the normal distribution. The strain at $50 \%$ of the UCS was mostly concentrated in the range of 0.0032 to 0.0034 and 0.0034 to 0.0036 ; the total of the two accounted for $60.8 \%$; the P-value was 0.107 . The strain at the maximum secant modulus was mostly distributed in the range of 0.0046 to 0.0048 , and the P-value was 0.469 . The P-values of the two types of strains were greater than 0.005 , indicating that they conformed to the typical normal distribution characteristics.

In summary, the three types of strain data all conformed to the normal distribution, indicating that the relationships between the three types of strain and the water saturation are independent of each other, i.e., the water saturation will not be affected by these three types of strain.
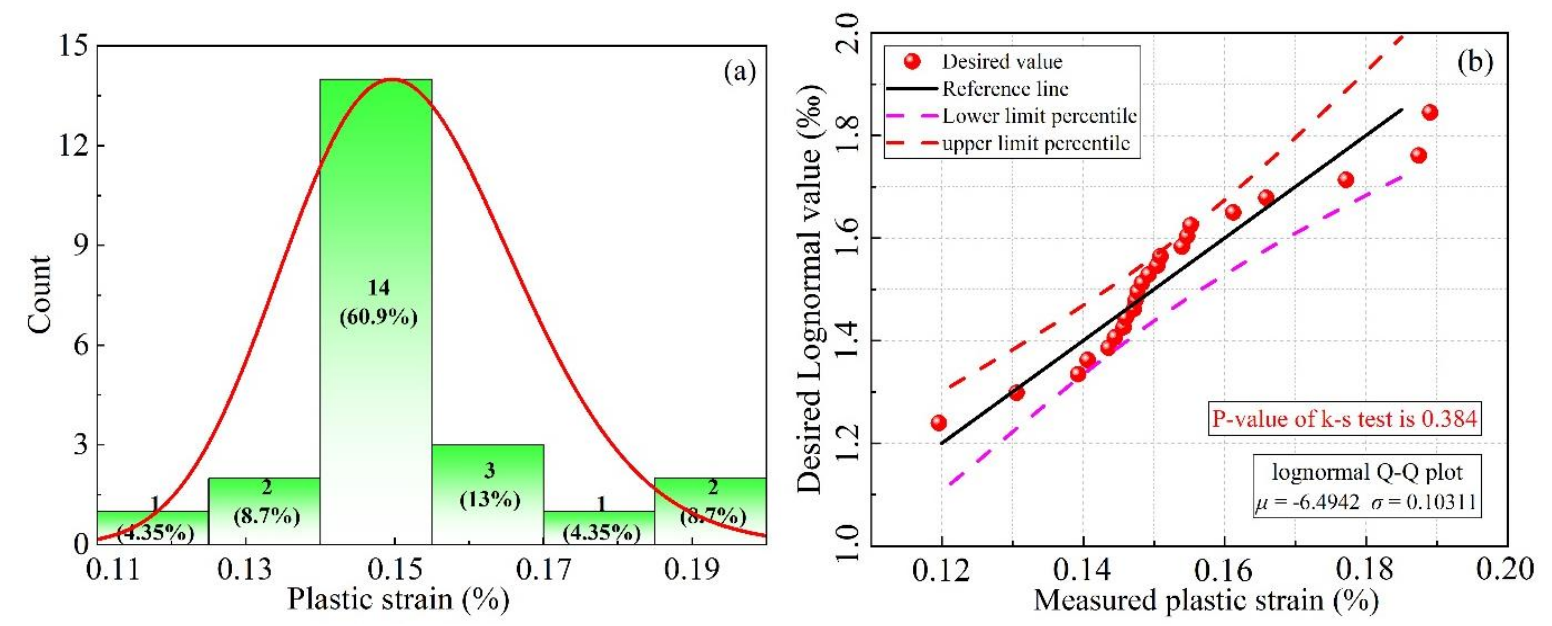

Figure 12: Plastic strain. (a) Histogram. (2) Q-Q plot.
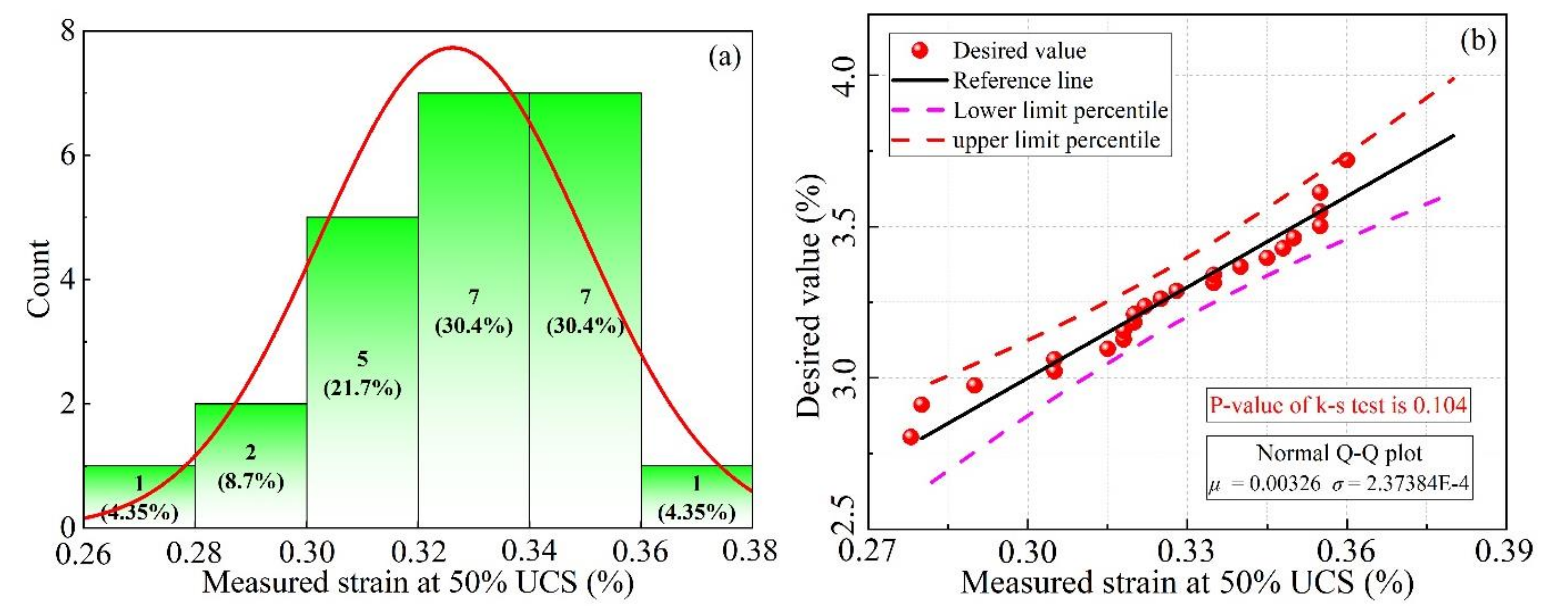

Figure 13: Strain at 50\% of the UCS. (a) Histogram. (2) Q-Q plot. 


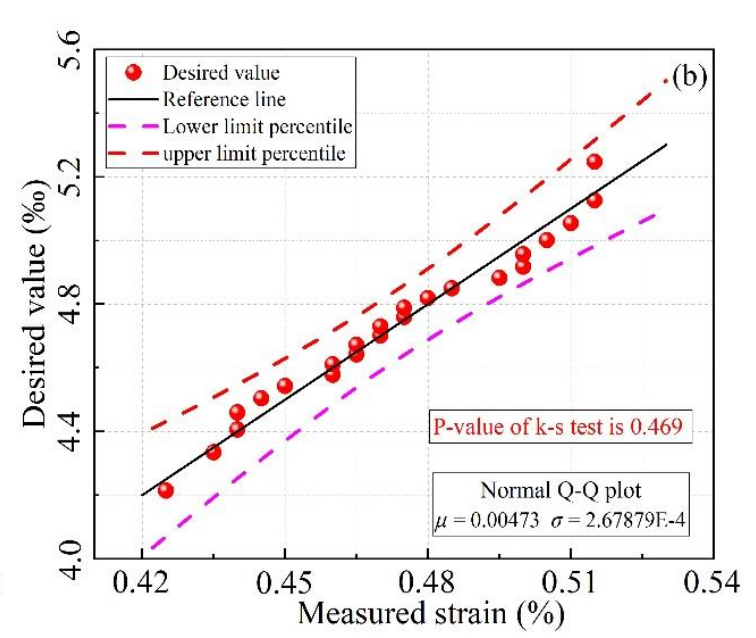

Figure 14: Strain at the maximum secant modulus. (a) Histogram. (2) Q-Q plot.

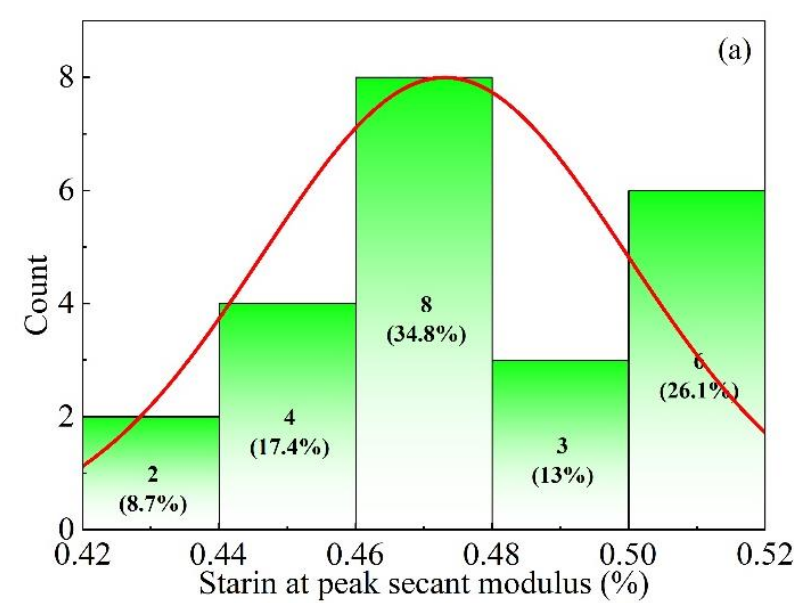

\subsection{Mechanism of CPB strength degradation}

The results in Sections 3.1 and 4.1 show that the peak stress of the CPB decreased exponentially with increasing water saturation, and the CPB strength difference between different water saturations decreased exponentially as the water saturation increased. Because $\mathrm{CPB}$ and concrete are both mixtures made of cement, particles, and water mixed in certain ratios, there are many similarities in their water saturation characteristics [48-50].

There are two principals' reasons for the strength change of the CPB with varying water saturation: the chemical corrosive action of water and the mechanical action of water. Due to the long curing time (60d), the internal hydration process was completed, and the chemical reaction had little effect on the strength. Thus, the strength difference was chiefly caused by the physical effects of the water. During the CPB drying process, the water in the inner capillaries gradually evaporated, and the capillaries shrank, resulting in an increase in capillary suction in the $\mathrm{CPB}$. When the $\mathrm{CPB}$ was treated with water saturation, capillary expansion was caused by the continuous penetration of the water into the internal capillary, and the capillary suction in the CPB was gradually reduced, resulting in an overall strength reduction. Additionally, the water permeation led to the loosening of the overall structure of the CPB and the deterioration of the overall strength of the CPB.

\subsection{Distribution characteristics of cracks}

Figure 15 shows the surface crack distribution of the CPB specimens with different water saturations. It can be seen from Figure 15 that increased water saturation led to an increased number and density of cracks. It can also be observed that most of the cracks were distributed around the CPB specimens' peripheries, and, with increasing water saturation, the cracks extended deeper into the center of the CPB specimens.
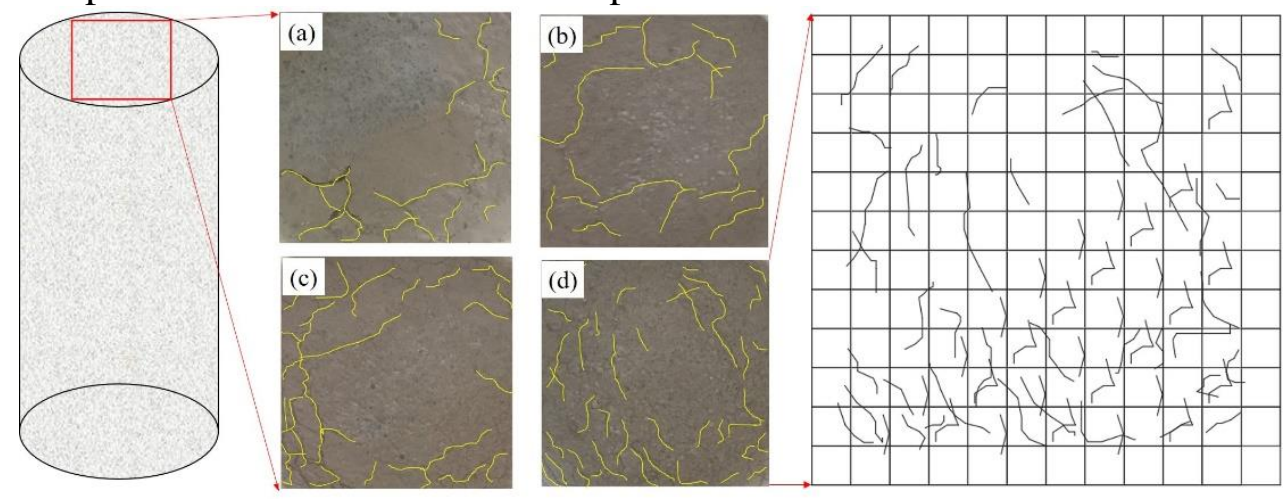
Figure 15: Distribution of the cracks in the CPB specimens with various water saturations. (a) $4.98 \%$; (b)

$$
9.32 \% \text {. (c) } 21.6 \% \text {. (d) } 32.8 \% \text {. }
$$

With the help of fractal theory [51-52], the fractal dimensions of the crack outlines in the CPB specimens with different water saturations were determined by the box-counting method, and the results are shown in Figure 16. It can be seen that the cracks in the CPB specimens with different water saturations demonstrated fractal characteristics. The fractal dimension, D, increased with increasing water saturation, and the change in the fractal dimension, D, is inverse to the change in strength. Using exponential, logarithmic, and power functions to fit the relationship between the fractal dimension and water saturation, it was found that the degree of fit of the exponential function was the highest. This revealed that the relationship between the fractal dimension of the cracks and the water saturation is an exponential function, expressed as:

$$
D=-0.23 e^{-0.042 w_{s}}+1.31 \quad(14)
$$

where $\mathrm{D}$ is the fractal dimension of the cracks in the CPB.

Further, the relationship between the UCS of the CPB and its fractal dimension was obtained, as shown in Figure 16. It was found that the UCS of the CPB decreased with increasing fractal dimension, and $\mathrm{R}^{2}$ was as high as 0.962 with linear fitting, demonstrating that they have a good linear function relationship.

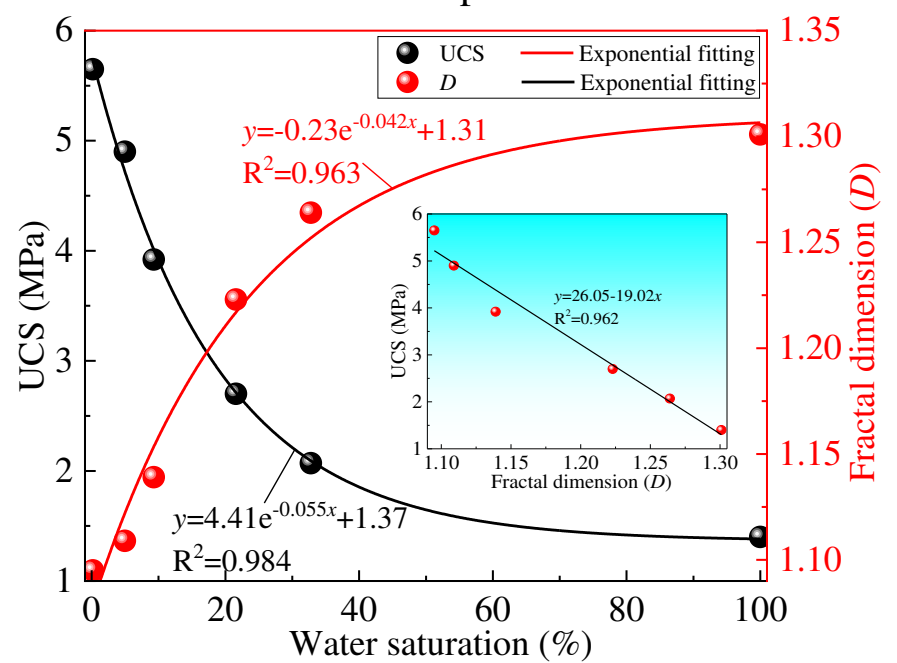

Figure 16: Relationship between the water saturation and the fractal dimension.

\section{Conclusions}

Water saturation has a great influence on the mechanical properties of CPB. In this paper, uniaxial compression tests were carried out on five kinds of CPB specimens with different water saturation. The influence of water saturation on CPB strength, deformation and apparent crack was discussed. Based on the research of this paper, the main conclusions are as follows:

(1) The deformation modulus of the CPB decreased with increasing water saturation. After the peak point, the strength of the CPB decreased rapidly when the water saturation was less than $20 \%$, and the strength decreased slowly when the water saturation was greater than $30 \%$.

(2) The relationship between the water saturation and the UCS, residual strength, peak strain, elastic strain, and strain ratio had an exponential function: $y=a_{1} e^{b_{1} x}+c_{1}$. The UCS, residual strength, peak strain, and elastic strain of the CPB decreased and the strain ratio of the CPB increased with increasing water saturation. There was no apparent relationship between the plastic strain and water saturation. 
(3) The secant modulus of the CPB decreased with increasing the water saturation, and it first increased and then decreased (the critical point was $0.5 \%$ ) with increasing strain. The $E_{50}$ decreased with increasing water saturation as an exponential function: $y=a_{3}+b_{3} e^{c_{3} x}$.

(4) The strength difference of the CPB decreased with increasing water saturation, and there was a strong exponential function relationship between them. The water saturation had little effect on the plastic strain, the $E_{50}$ strain, or the maximum secant modulus strain.

(5) Most of the cracks in the CPB specimens with different water saturations were distributed around the periphery of the specimens. The greater the water saturation was, the more cracks that were present in the CPB. The fractal dimension, $D$, of the cracks in the CPB increased exponentially with increasing water saturation. The fractal dimension, $D$, has a negative linear correlation with the UCS.

This study considered the effects of water saturation on the mechanical properties of CPB and demonstrated that water saturation has apparent degradative effects on the mechanical properties of CPB. However, the influence of water saturation on the mechanical properties of CPB is closely related to the cement-to-tailings ratio, slurry concentration, and curing age, among other factors. This study can provide a scientific reference for the strength design of $\mathrm{CPB}$ when the underground is rich in water.

\section{Author Contributions}

J.W. and J.F. analyzed the experimental data and initiated the writing of the paper; W.D. modified the manuscript; Y.Z. corrected the English writing.

\section{Funding Statement}

This research was supported the National Natural Science Foundation of China (Grant No. 51974012), the National Natural Science Foundation of China Youth Fund (51804016), and the Fundamental Research Funds for the Central Universities (FRF-BD-19-005A).

\section{Acknowledgments}

The experimental works described in this study were conducted at the Key Laboratory of High-Efficient Mining and Safety of Metal Mines of the Ministry of Education in the University of Science and Technology Beijing. The authors gratefully acknowledge the staff and students at the laboratory for technical help during testing.

\section{Conflicts of Interest}

The authors declare that there is no conflict of interest regarding the publication of this paper.

\section{References}

[1] A. Tariq, E.K. Yanful, A review of binders used in cemented paste tailings for underground and surface disposal practices, J. Environ. Manag. 131 (8) (2013) 138-149.

[2] C. Qi, A. Fourie, Q. Chen, Neural network and particle swarm optimization for predicting the unconfined compressive strength of cemented paste backfill, Constr. Build. Mater. 159 (2018) 473478. 
[3] L. Liu, Z.Y. Fang, C.C. Qi, B. Zhang, L.J. Guo, K.I. Song. Experimental investigation on the relationship between pore characteristics and unconfined compressive strength of cemented paste backfill, Constr. Build. Mater. 179 (2018) 254-264.

[4] W. Zhu, J. Xu, J. Xu, D. Chen, J. Shi, Pier-column backfill mining technology for controlling surface subsidence, Int. J. Rock Mech. Min. Sci. 96 (2017) 58-65.

[5] W. Sun, H.J. Wang, K.P. Hou, Control of waste rock-tailings paste backfill for active mining subsidence areas, Journal of Cleaner Production. 171 (10) (2018) 567-579.

[6] X. Li, J. Du, L. Gao, S. He, L. Gan, C. Sun, Y. Shi, Immobilization of phosphogypsum for cemented paste backfill and its environmental effect, J. Clean. Prod. 156 (2017) 137-146.

[7] L. Li, M. Aubertin, Numerical Investigation of the Stress State in Inclined Backfilled Stopes, International Journal of Geomechanics. 9 (2) (2009) 52-62.

[8] G.L. Xue, E. Yiimaz, W.D. Song, E. Yilmaz, Influence of fiber reinforcement on mechanical behavior and microstructural properties of cemented tailings backfill, Construction and Building Materials. 213 (2019) 275-285.

[9] S.H. Yin, Y.J. Shao, A.X. Wu, Z.Y. Wang, L.H. Yang, Assessment of expansion and strength properties of sulfidic cemented paste backfill cored from deep underground stopes, Construction and Building Materials. 230 (2020) 116983.

[10] C.D. Min, X.B. Li, S.Y He, S.T. Zhou, S. Yang, Y. Shi, Effect of mixing time on the properties of phosphogypsum-based cemented backfill, Construction and Building Materials. 210 (20) (2019) 564573.

[11] P. Yang, L. Li, Investigation of the short-term stress distribution in stopes and drifts backfilled with cemented paste backfill, Int. J. Min. Sci. Technol. 25 (05) (2015) 721-728.

[12] D.R. Tesarik, J.B. Seymour, T.R. Yanske,. Long-term stability of a backfilled room-and-pillar test section at the Buick Mine, Missouri, USA, Int. J. Rock Mech. Min. Sci. 46 (7) (2009) 1182-1196.

[13] Q.L. Yao, F.T. Zhang, X.L. Ding, L. Zhang, G. Jiang, Experimental research on instability mechanism of silty mudstone roofs under action of water and its application, Procedia Earth Planet. Sci. 1 (1) (2009) 402-408.

[14] M. Li, J.X. Zhang, Z. Liu, X. Zhao, P. Huang, Mechanical analysis of roof stability under nonlinear compaction of solid backfill body, International Journal of Mining Science and Technology. 26 (5) (2016) 863-868.

[15] X.Y. Zhang, M.Y. Xu, L. Liu, C. Huan, Y.J. Zhao, C.C. Qi. Experimental study on thermal and mechanical properties of cemented paste backfill with phase change material, Journal of Materials Research and Technology. 9 (2) (2020) 2164-2175.

[16] L.H. Yang, H.J. Wang, A.X. Wu, H. Li, T. Bruno, X. Zhou, X.T. Wang, Effect of mixing time on hydration kinetics and mechanical property of cemented paste backfill, Construction and Builing Materials. 247 (30) (2020) 118516.

[17] J.F. Hou, Z.P. Guo, W.Z. Liu, Y.X. Zhang, Mechanical properties and meso-structure response of cemented gangue-fly ash backfill with cracks under seepage- stress coupling, Construction and Builing Materials. 250 (30) (2020) 118863.

[18] M.B.C. Mangane, R. Argane, R. Trauchessec, A. Lecomte, M. Benzaazoua, Influence of superplasticizers on mechanical properties and workability of cemented paste backfill, Minerals Enginnering. 116 (15) (2018) 3-14. 
[19] Y.H. Zhang, X.M. Wang, C. Wei, Q.L. Zhang, Dynamic mechanical properties and instability behavior of layered backfill under intermediate strain rates, Transactions of Nonferrous Metals Society of China. 27 (7) (2017) 1608-1617.

[20] M. Benzaazoua, J.F. Fiset, B. Bussiere, M. Villeneuve, B. Plante, Sludge recycling within cemented paste backfill: Study of the mechanical and leachability properties, Minerals Enginnering. 19 (2006) 420-432.

[21] S. Cao, W.D. Song, E. Yilmaz, Influence of structural factors on uniaxial compressive strength of cemented tailings backfill, Construction and Building Materials. 174 (2018) 190-201.

[22] S. Cao, W.D. Song, Effect of filling interval time on the mechanical strength and ultrasonic properties of cemented coarse tailing backfill, International Journal of Mineral Processing. 166 (2017) 62-68.

[13] M. Full, M. Benzaazoua, Modeling the effect of sulphate on strength development of paste backfill and binder mixture optimization, Cement and Concrete Research. 35 (2005) 301-314.

[24] Z.X. Liu, T. Luo, X. Li, X.B. Li, Z. Huai, S.F. Wang, Construction of reasonable pillar group for undersea mining in metal mine, Transactions of Nonferrous Metals Society of China. 28 (4) (2018) 757-765.

[25] W.Z. Liang, G.Y. Zhao, H. Wu, Y. Chen, Optimization of mining method in subsea deep gold mines: A case study, Transactions of Nonferrous Metals Society of China. 29 (10) (2019) 2160-2169.

[26] B. Liu, Y.T. Gao, A.B. Jin, X. Wang, Influence of water loss on mechanical properties of superfine tailing-blast-furnace slag backfill, Construction and Building Materials. 246 (20) (2020) 118482.

[27] A.X. Wu, Y. Wang, H.J. Wang, S.H. Yin, X.X. Miao, Coupled effects of cement type and water quality on the properties of cemented paste backfill, International Journal of Mineral Processing. 143 (10) (2015) (65-71).

[28] J.P. Zuo, Z.J. Hou, Z.Q. Xiong, C. Wang, H.Q. Song, Influence of different W/C on the performances and hydration progress of dual liquid high water backfilling material, Construction and Building Materials. 190 (30) (2018) 910-917.

[29] D.Y. Wei, C.F. Du, Y.F. Lin, B.M. Chang, Impact factors of hydration heat of cemented tailings backfill based on multi-index optimization, Case Studies in Thermal Engineering. 18 (2020) 100601.

[30] J.R. Zheng, X.X Sun, L.J. Guo, S.M. Zhang, J.Y. Chen, Strength and hydration products of cemented paste backfill from sulphide-rich tailings using reactive $\mathrm{MgO}$-activated slag as a binder, Construction and Building Materials. 203 (10) (2019) 111-119.

[31] S.J. Chen, Z.W. Du, Z. Zhang, H.W. Zhang, Z.G. Xia, F. Feng, Effects of chloride on the early mechanical properties and microstructure of gangue-cemented paste backfill, Construction and Building Materials. 235 (28) (2020) 117504.

[32] L. Liu, C. Zhu, C.C. Qi, B. Zhang, K. Song, A microstructural hydration model for cemented paste backfill considering internal sulfate attacks, Construction and Building Materials. 211 (30) (2019) 99108 .

[33] D. Wu, Y.L. Zhang, C. Wang, Modeling the thermal response of hydrating cemented gangue backfill with admixture of fly ash, Thermochimica Acta. 623 (10) (2016) 86-94.

[34] Y. Zhao, A. Taheri, M. Karakus, Z.W. Chen, A. Deng, Effects of water content, water type and temperature on the rheological behaviour of slag-cement and fly ash-cement paste backfill, International Journal of Mining Science and Technology. 2020 In press. 
[35] Y.L. Nie, X.J. Wang, G.L. Huang, S.C. Li, X. Feng, S.R. Cao, Strength and Damage Model Analysis of Pure Tailings Cemented Filling Body with Different Water Content. Bulletin of the Chinese Ceramic Society. 37 (6) (2018) 2008-2013.

[36] J.W. Liu, W.H. Sui, D.Y. Zhang, Q.J. Zhao, Durability of water-affected paste backfill material and its clean use in coal mining, Journal of Cleaner Production. 250 (2020) 119576.

[37] Y.Q. Hou, Y.P. Zhang, L. Wang, X.G. Zou, Research on dynamic load failure characteristics of dry and saturated backfill, Industrial Minerals \& Processing. 7 (2017) 38-45.

[38] A. Rabat, M. Cano, R. Tomas, Effect of water saturation on strength and deformability of building calcarenite stones: Correlations with their physical properties, Construction and Building Materials. 232 (2020) 117259.

[39] L. Zhuang, K.Y. Kim, M. Diaz, S. Yeom, Evaluation of water saturation effect on mechanical properties and hydraulic fracturing behavior of granite, International Journal of Rock Mechanics and Mining Sciences. 130 (2020) 104321.

[40] X.J. Du, G.R. Feng, T.Y. Qi, Y.X. Guo, Y.J. Zhang, Z.H. Wang, Failure characteristics of large unconfined cemented gangue backfill structure in partial backfill mining, Construction and Building Materials. 194 (2019) 257-265.

[41] A. Torok, B. Vasarhelyi, The influence of fabric and water content on selected rock mechanical parameters of travertine, examples from Hungary, Eng. Geol. 115 (3-4) (2010) 237-245.

[42] A.R. Najibi, M. Ghafoori, G.R. Lashkaripour, M.R. Asef, Empirical relations between strength and static and dynamic elastic properties of Asmari and Sarvak limestones, two main oil reservoirs in Iran, J. Pet. Sci. Eng. 126 (2015) 78-82.

[43] V. Brotons, R. Tomás, S. Ivorra, A. Grediaga, Relationship between static and dynamic elastic modulus of calcarenite heated at different temperatures: the San Julián's stone, Bull. Eng. Geol. Environ. 73 (3) (2014) 791-799.

[44] A.B. Hawkins, B.J. McConnell, Sensitivity of sandstone strength and deformability to changes in moisture content, Quarterly J. Eng. Geology.25 (1992) 115-130.

[45] B. Vásárhelyi, Some observations regarding the strength and deformability of sandstones in case of dry and saturated conditions, Bull. Eng. Geol. Env.62 (2003) 245-249.

[46] S. Lem, P. Onghena, L. Verschaffel, W.V. Dooren, The heuristic interpretation of box plots, Learning and Instruction. 26 (2013) 22-35.

[47] H.F.J. Theart, R. Ghavami-Riabi, H. Mouri, P. Graser, Applying the box plot to the recognition of footwall alteration zones related to VMS deposits in a high-grade metamorphic terrain, South Africa, a lithogeochemical exploration application, Geochemistry. 71 (2) (2011) 143-154.

[48] J.M. Torrenti, L. Granger, M. Diruy, P. Genin, 1997. Modé1isation du retrait du béton en ambiance variable, Revue Française de Génie Civil. 1 (4) (1997) 687-698.

[49] I. Yurtdas, N.Burlion, F. Skoczylas, Experimental characterisation of the drying effect on uniaxial mechanical behavior of mortar, Materials and Structures. 37 (267) (2004) 170-176.

[50] N. Burlion, F. Bourgeois, J.F. Shao, Effects of desiccation on mechanical behavior of concrete, Cement and Concrete Composites. 27 (3) (2005) 367-379. 
594

[51] T. Liu, X.N. Zhang, Z. Li, Z.Q. Chen, Research on the homogeneity of asphalt pavement quality using X-ray computed tomography (CT) and fractal theory, Construction and Building Materials. 68 (2014) 587-598.

[52] J.M. Wang, L.L. Guo, Z.K. Bai, L.L. Yang, Using computed tomography (CT) images and multi-fractal theory to quantify the pore distribution of reconstructed soils during ecological restoration in opencast coal-mine, Ecological Engineering. 92 (2016) 148-157. 
Figures

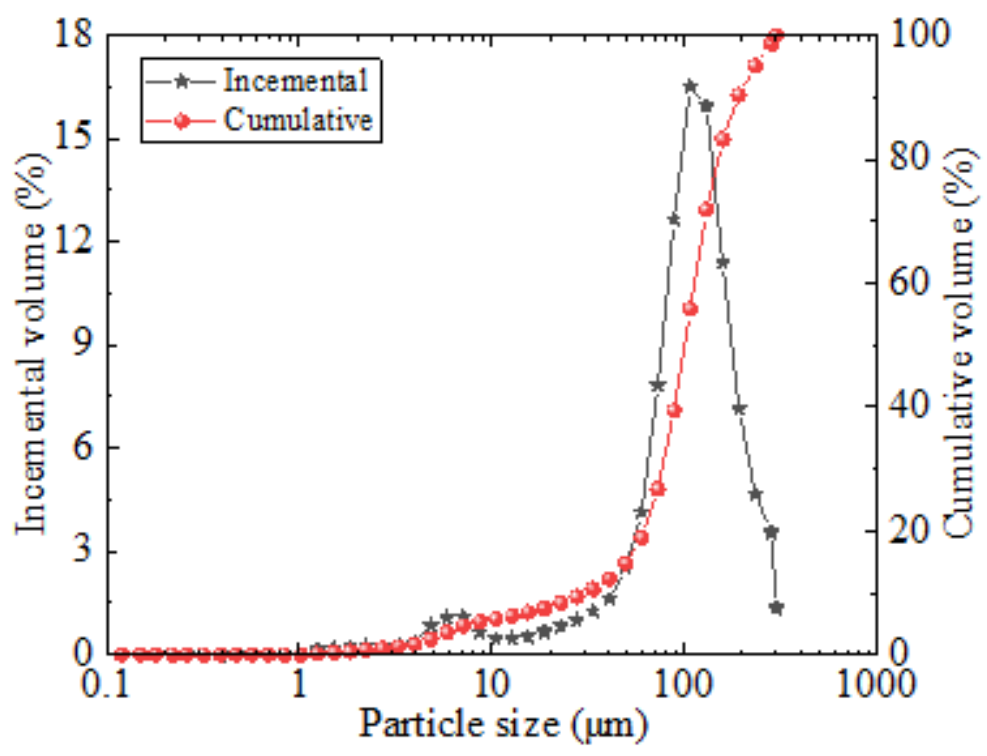

Figure 1

Incremental and cumulative PSD curves of the tailings.

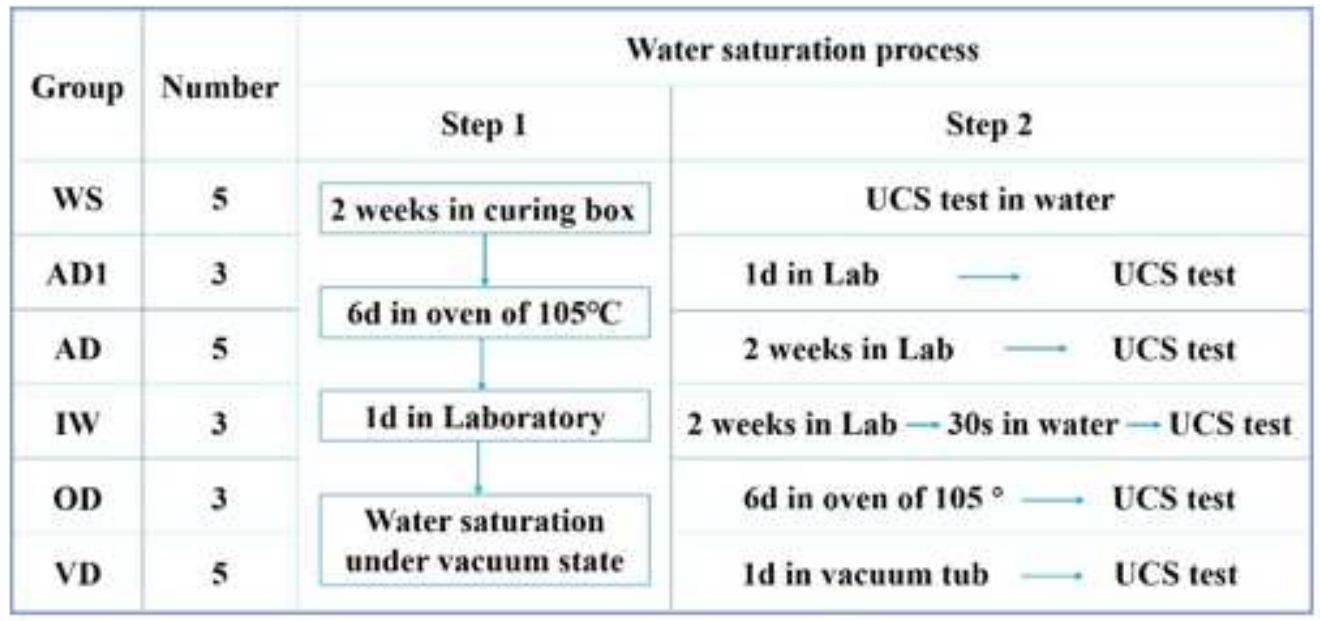

Figure 2

CPB specimen water saturation processes. 


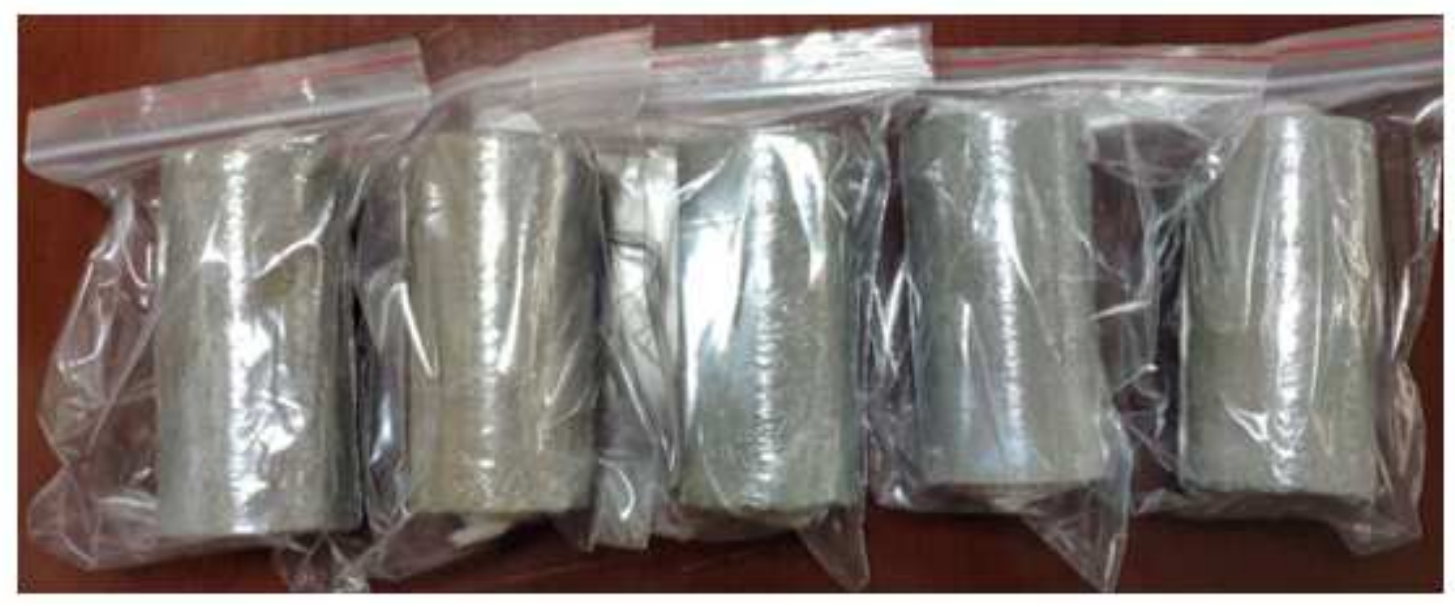

\section{Figure 3}

CPB specimens are sealed in plastic bags.

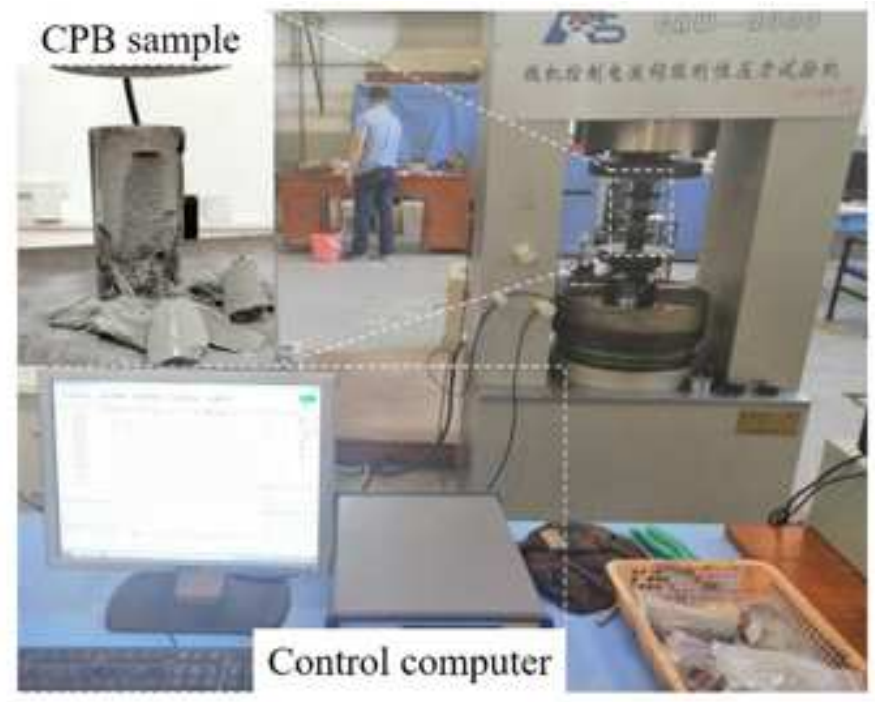

Figure 4

GAW-2000 electro-hydraulic servo testing machine. 


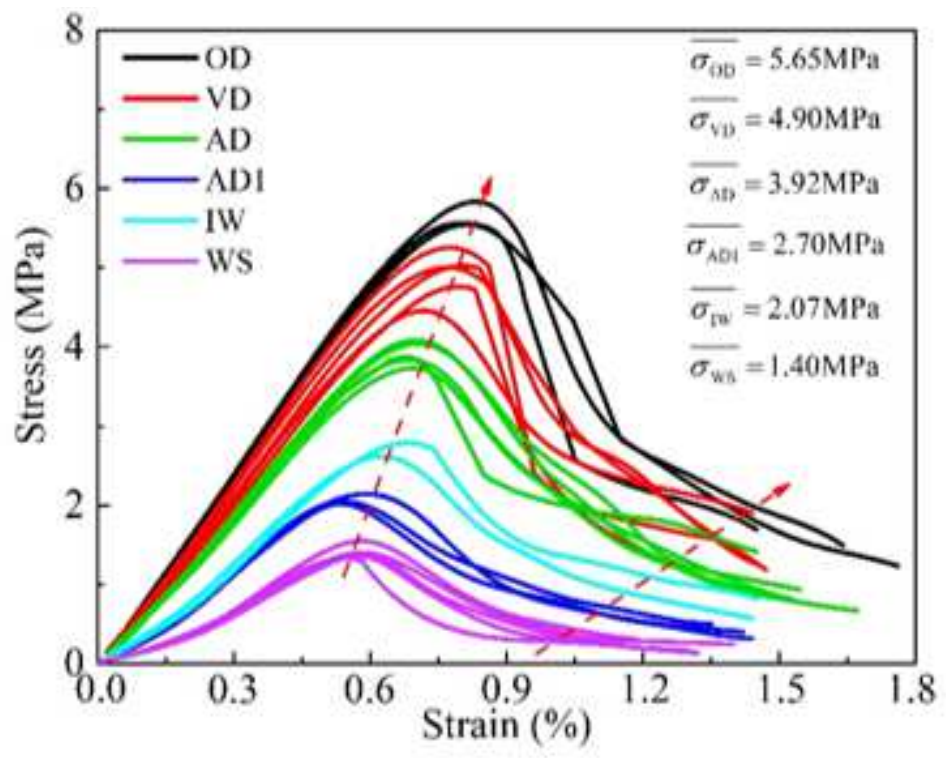

Figure 5

Stress-strain curve of the specimens with different water saturation values.
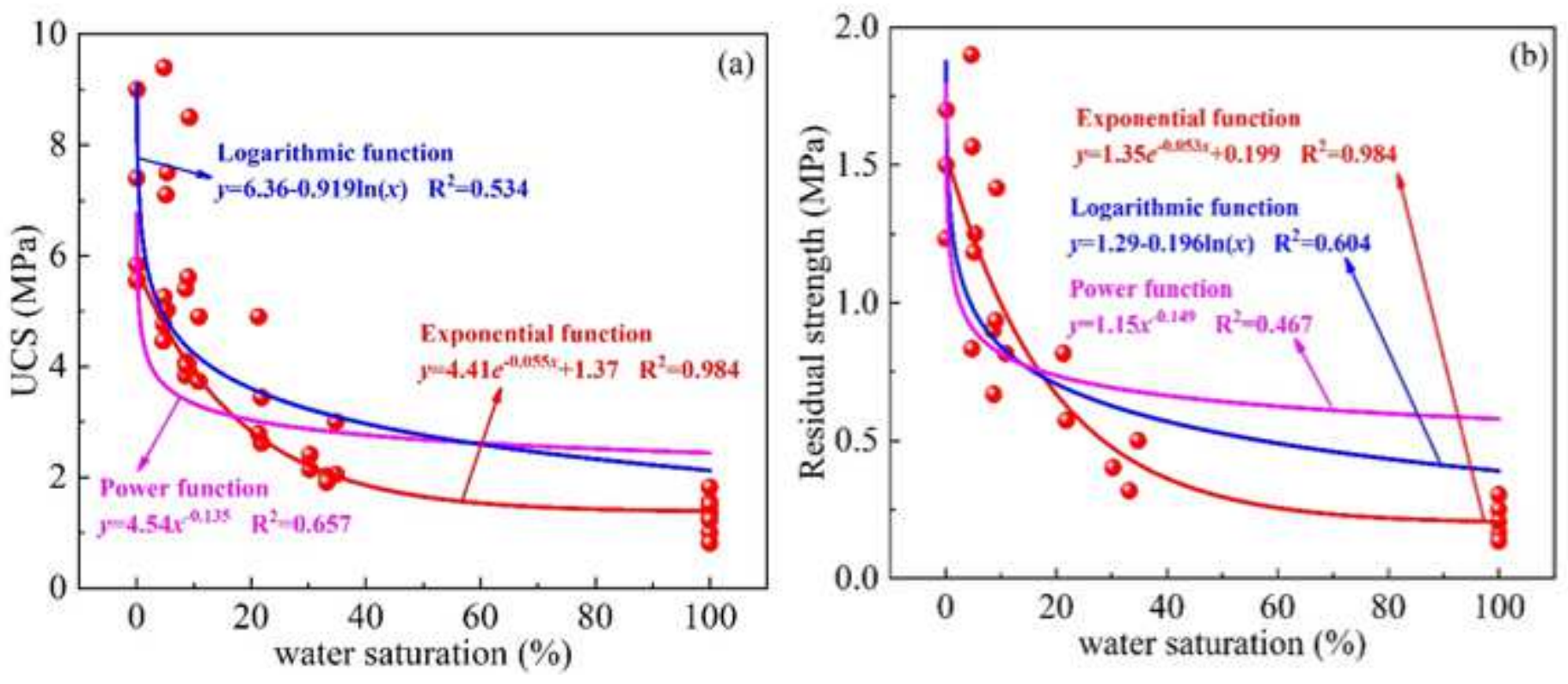

Figure 6

Relationship between the strength and water saturation of the CPB specimens. (a) UCS. (b) residual strength. 

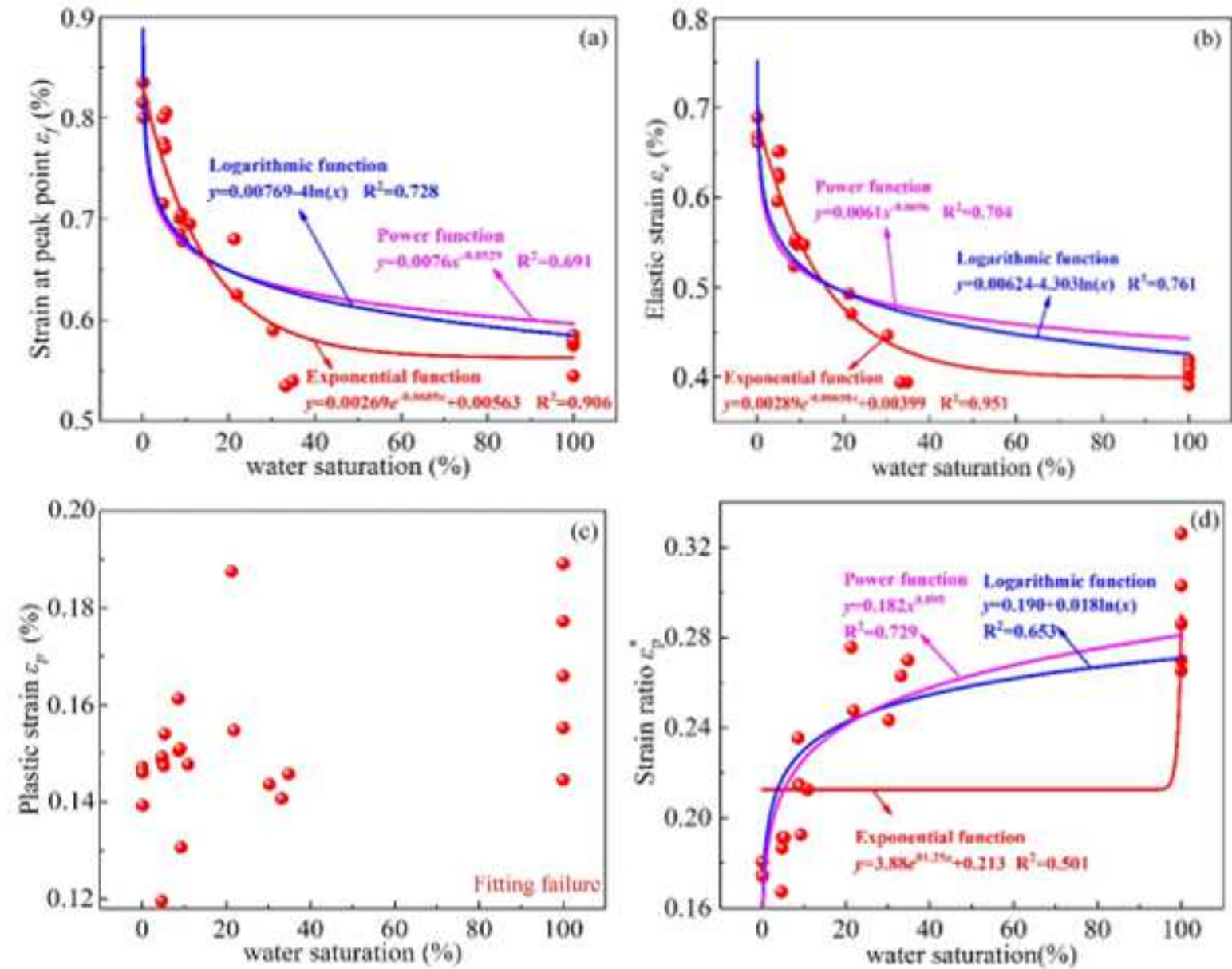

\section{Figure 7}

Relationship between the strains and water saturation. (a) $\varepsilon f$. (b) $\varepsilon e$. (c) $\varepsilon p$. (d) $\varepsilon p^{*}$.
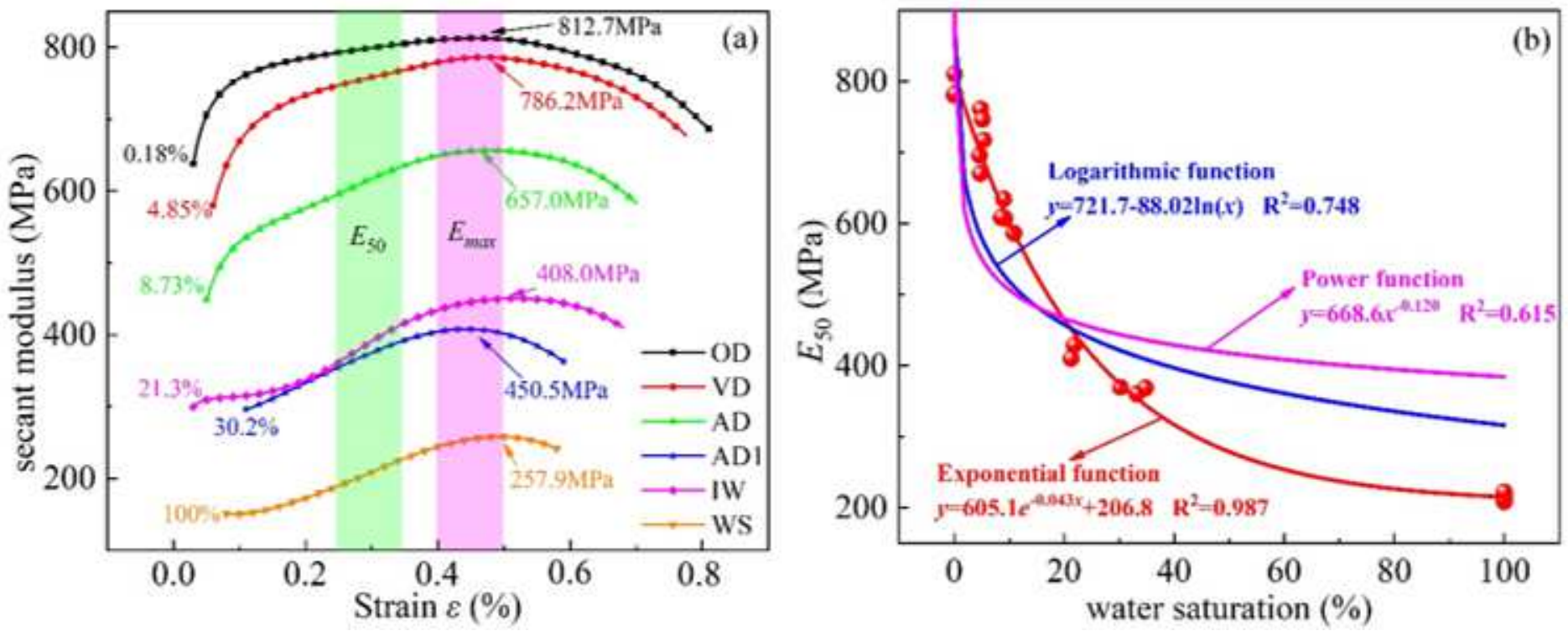

Figure 8

The evolution of the CPB modulus. (a) secant modulus. (b) E50. 


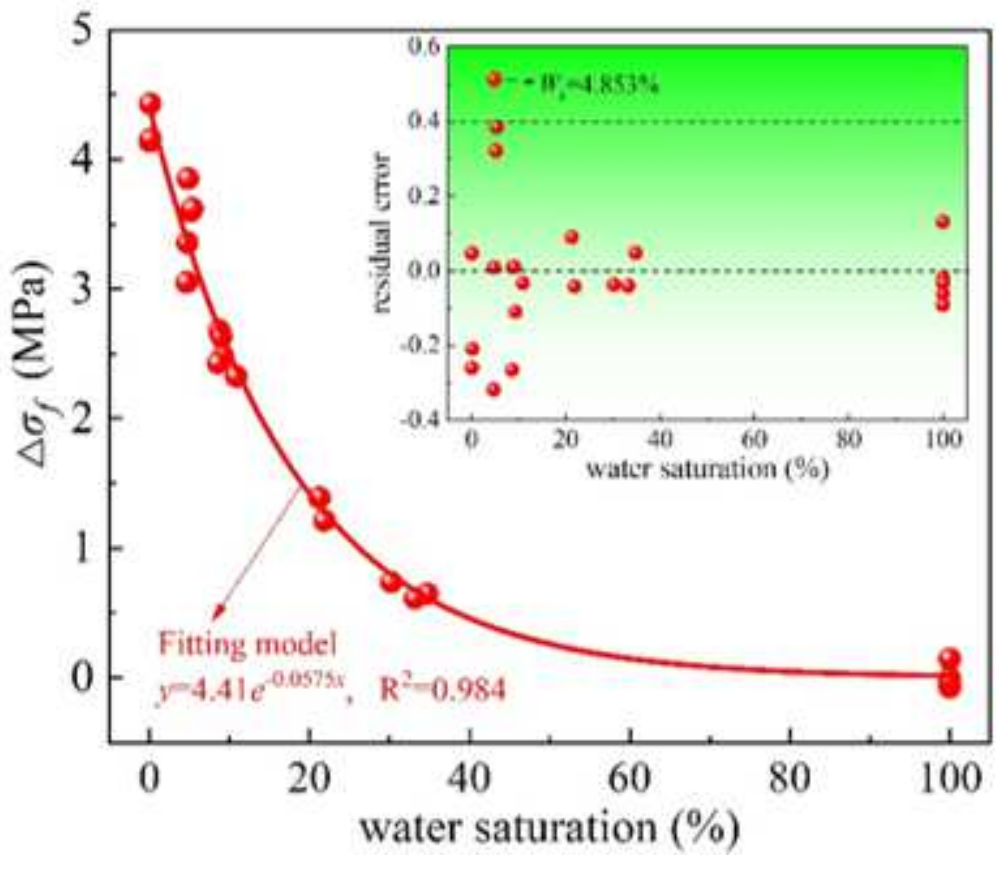

Figure 9

Relationship between the strength difference and water saturation.

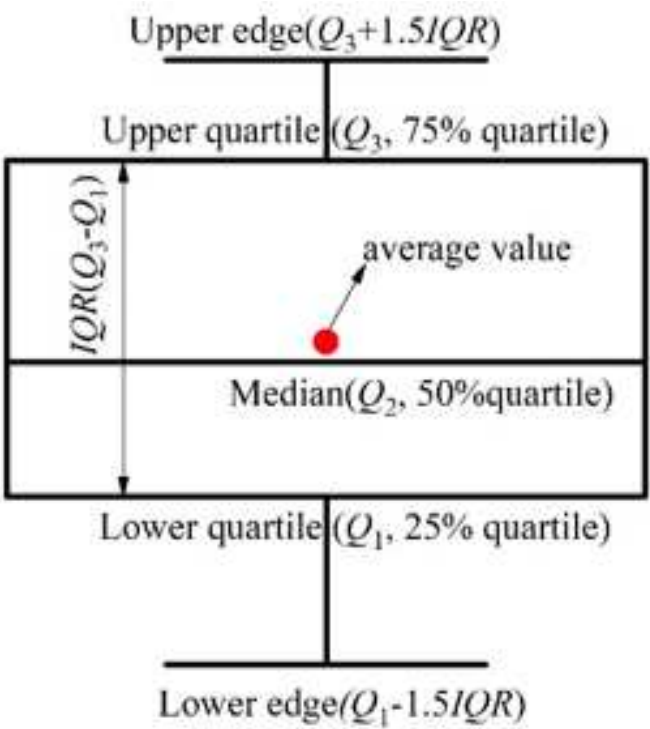

Figure 10

Box plot. 

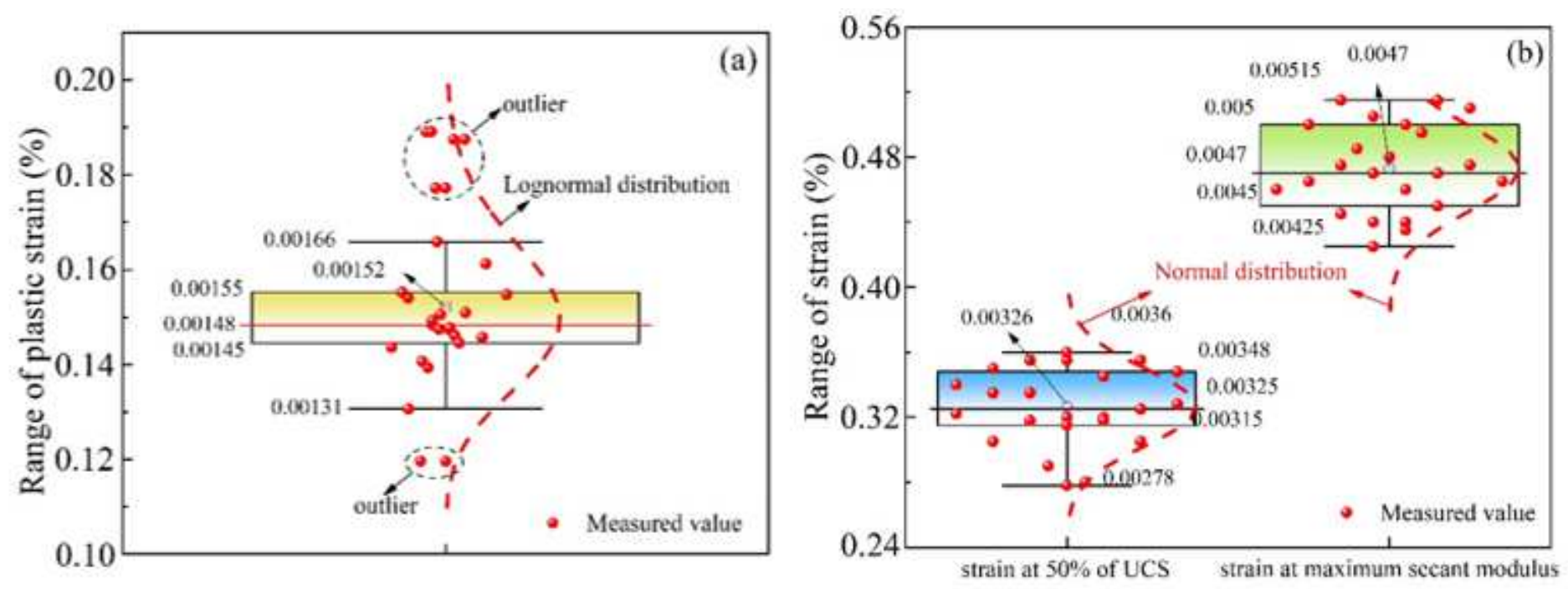

Figure 11

Box plots of (a) plastic strain and (b) strain at E50 and maximum secant modulus.
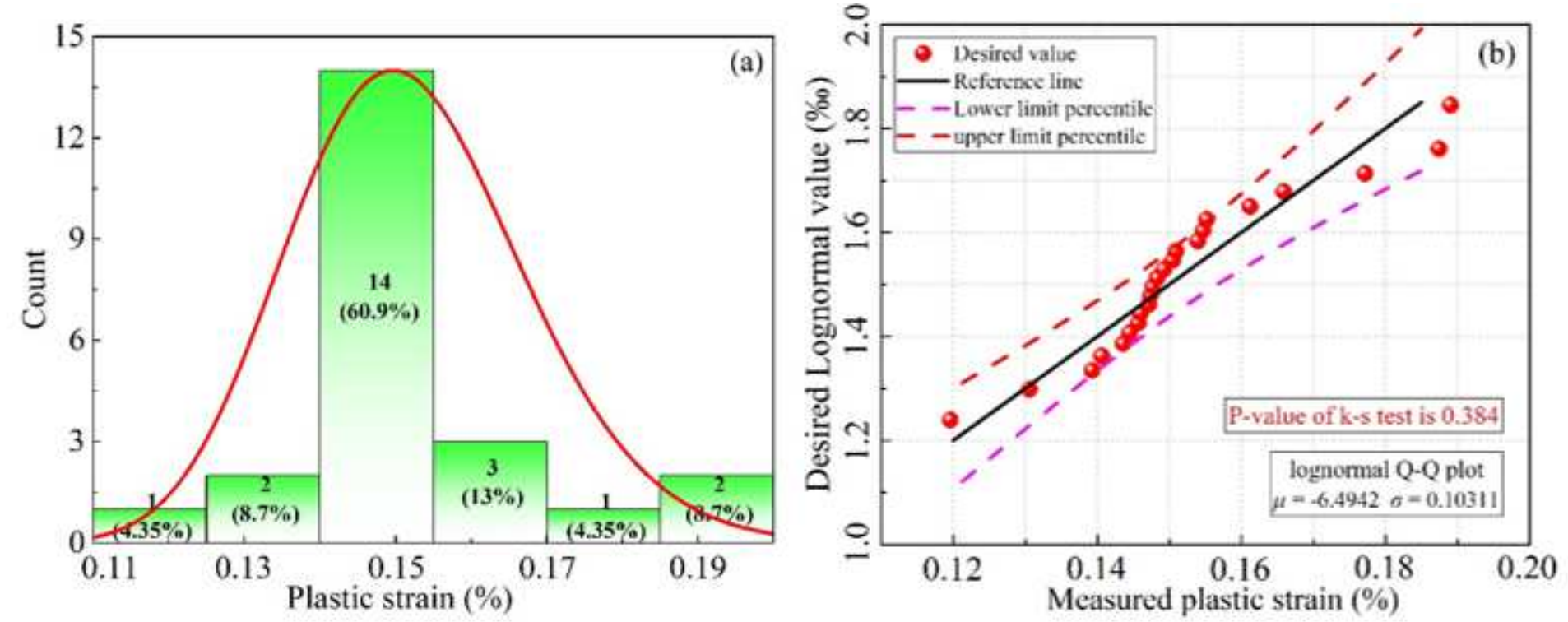

Figure 12

Plastic strain. (a) Histogram. (2) Q-Q plot. 

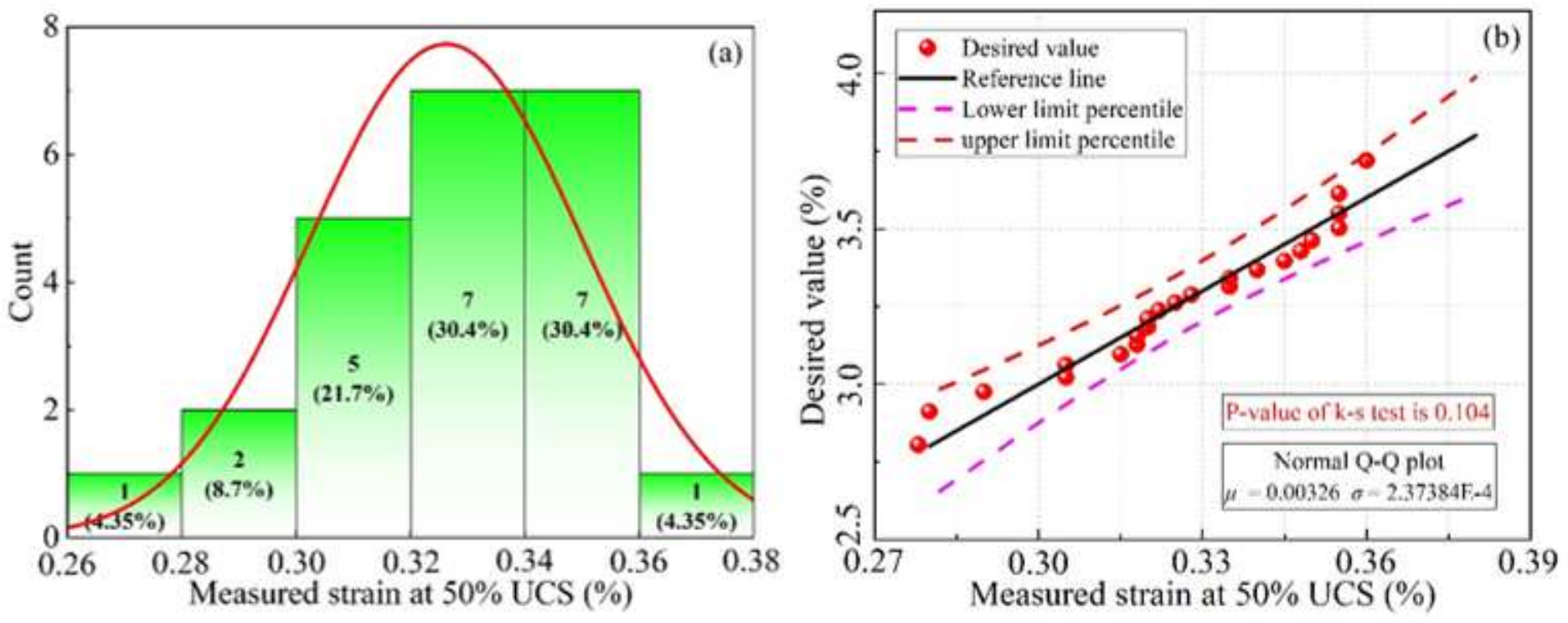

Figure 13

Strain at $50 \%$ of the UCS. (a) Histogram. (2) Q-Q plot.
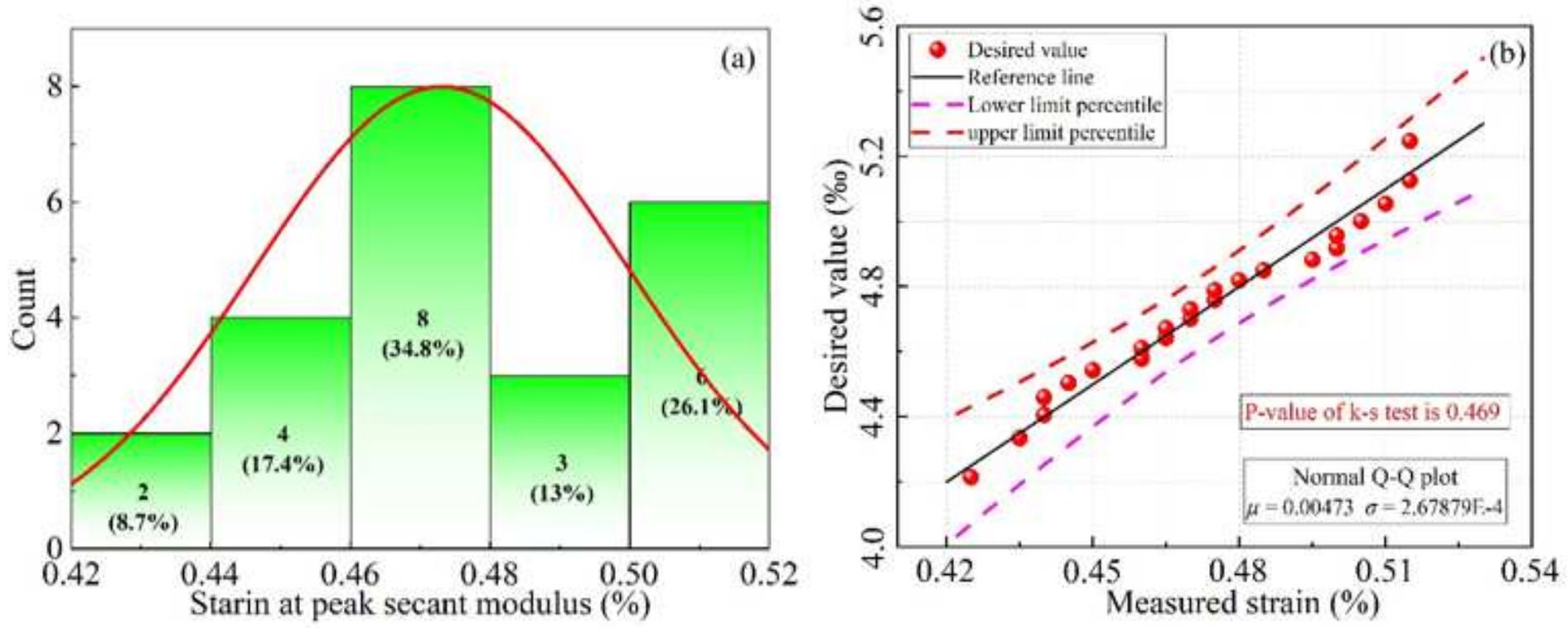

Figure 14

Strain at the maximum secant modulus. (a) Histogram. (2) Q-Q plot. 


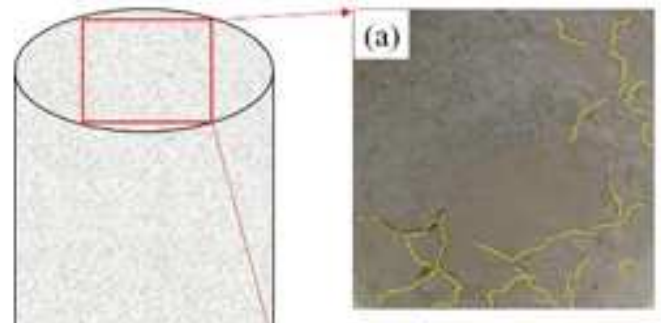

(c)

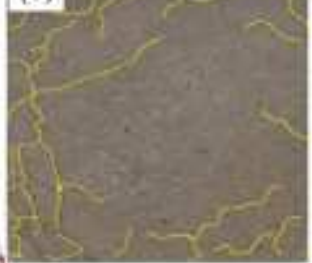

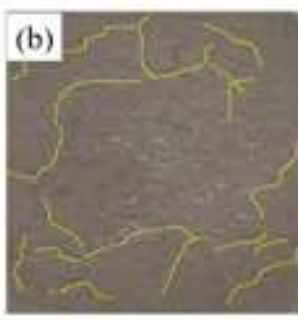

(d)

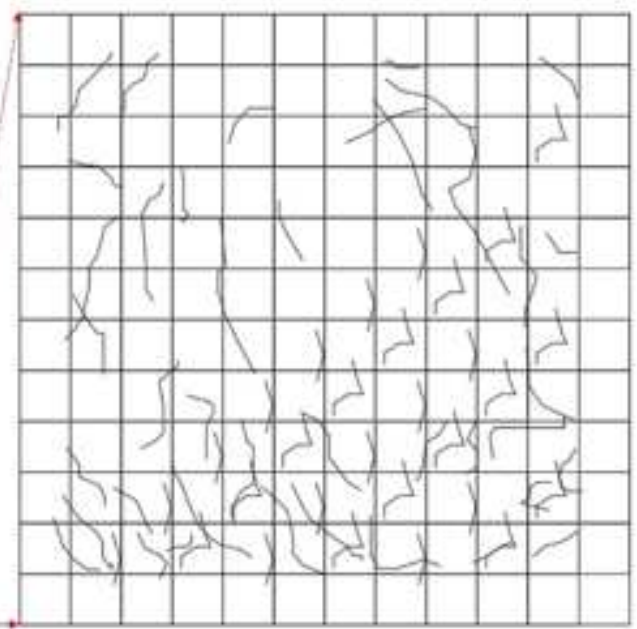

Figure 15

Distribution of the cracks in the CPB specimens with various water saturations. (a) $4.98 \%$; (b) $9.32 \%$. (c) $21.6 \%$. (d) $32.8 \%$.

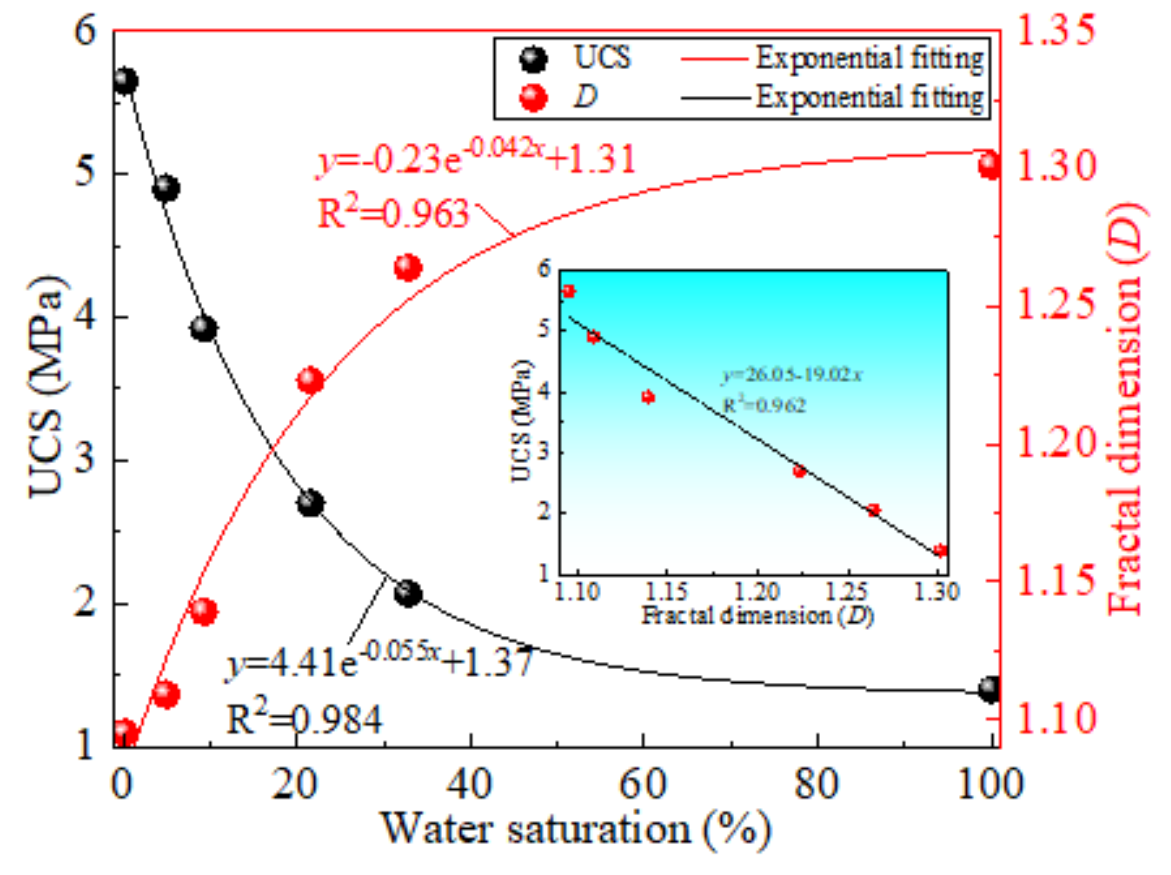

Figure 16

Relationship between the water saturation and the fractal dimension. 